\title{
Control without controllers: Towards a distributed neuroscience of executive control
}

\author{
Benjamin R. Eisenreich, Rei Akaishi, and Benjamin Y. Hayden \\ Brain and Cognitive Sciences and Center for Visual Science \\ University of Rochester \\ Rochester, NY. 14627
}

\section{Contact Information:}

Benjamin R. Eisenreich

Brain and Cognitive Sciences, Meliora Hall

University of Rochester, Rochester, NY. 14627

Email: benjaminr.eisenreich@gmail.com

\section{Acknowledgements:}

This work is supported by a CAREER award from NSF (BCS1253576) and a R01 from NIH (DA038615) to BYH. R.A. is supported by Research Fellowships for Young Scientists from the Japan Society for the Promotion of Science (JSPS). We thank Tom Seeley for patient explanations and Amanda Oglesby-Sherrouse for introducing us to the wonderful world of bioluminescent bacteria. 


\begin{abstract}
Executive control refers to the regulation of cognition and behavior by mental processes and is a hallmark of higher cognition. Most approaches to understanding its mechanisms begin with the assumption that our brains have anatomically segregated and functionally specialized control modules. The modular approach is intuitive: control is conceptually distinct from basic mental processing, so an organization that reifies that distinction makes sense. An alternative approach sees executive control as selforganizing principles of a distributed organization. In distributed systems, control and controlled processes are co-localized within large numbers of dispersed computational agents. Control then is often an emergent consequence of simple rules governing the interaction between agents. Because these systems are unfamiliar and unintuitive, here we review several well-understood examples of distributed control systems, group living insects and social animals, and emphasize their parallels with neural systems. We then reexamine the cognitive neuroscience literature on executive control for evidence that its neural control systems may be distributed.
\end{abstract}


19

20

21

22

23

24

25

26

27

28

29

30

31

32

33

34

35

36

37

38

39

40

41

42

43

44

45

46

47

48

49

50

51

52

53

54

55

56

57

58

59

60

61

62

63

64

\section{Main Text}

\section{Introduction}

Executive control refers to the brain's ability to regulate its own processing. It coordinates multiple competing demands, controls attention, gates working memory, and encodes and retrieves long-term memories. It also maintains and switches task set, inhibits disadvantageous actions, and regulates the explore/exploit tradeoff and curiosity (Miller \& Cohen, 2001; Shiffrin \& Schneider, 1977; Braver \& Barch, 2006; Cole \& Schneider, 2007; Miller, 2000a; Ridderinkhof, van den Wildenberg, Segalowitz, \& Carter, 2004; Kidd \& Hayden, 2015). Understanding executive control is critical for understanding self-control and its failures (Aron, Robbins, \& Poldrack, 2014; Knoch \& Fehr, 2007; Hare \& Rangel, 2009). More broadly, failures of executive control are hallmarks of many diseases, including addiction, depression, and obsessive-compulsive disorder, and successful treatments of these diseases often target executive control (e.g. Milad \& Rauch, 2012; Ursu et al., 2003; Volkow \& Fowler, 2000; Kalivas \& Volkow, 2005).

A brain can be understood as a control system, a collection of interacting components within an organizational structure that produces adaptive actions based on information about the current state of the internal and external worlds (Pezzulo \& Cisek, 2016; Gallistel, 2013; Lashley, 1951). As we process sensory inputs and generate actions, the brain monitors that processing and, if it detects the need to change, it regulates it. But how is executive control in the brain implemented by the interactions of its constituent parts, individual neurons?

\section{Modular and distributed control systems}

The standard approach to understanding control starts with the assumption of modularity. In a modular control system, regulation is derived from a central controller, which is a discrete subsystem with a specialized function. In a modular system, it is theoretically possible to draw a line through anatomical space separating localized control regions or circuits (often the prefrontal cortex and striatum) from more basic processing (caudal cortical) regions (Botvinick et al, 2001; Miller \& Cohen 2001; Miller, 2000). This specialization means that control regions (or networks) regulate, but do not participate in, the underlying stimulus-to-action transformation processes (Figure 1). Such a view is consistent with a long tradition emphasizing the brain's modular architecture (Fodor, 1983; Minsky, 1988; Kanwisher, Mcdermott, \& Chun 1997; Bertolero, Yeo, \& Desposito 2015). But it is not the only possible view.

The alternative approach envisions executive control as distributed processes in which there is no dedicated and specialized controller (Figure 1). Instead, in a distributed control system, regulatory functions are dispersed across a large number of individual elements or carried out by the interaction among them (Couzin, 2009; Sumpter, 2006). In most such systems control elements are co-localized with processing elements, and those elements have somewhat autonomous function. For this reason they are often called agents. These agents (or any other individual elements in a distributed control system) sense the properties of their local environment and adjust their own behavior based on 
65 simple rules. Agents normally have no knowledge of the overall state of the system, and the response of the system as a whole is often qualitatively dissimilar from those of the elements. In other words, in such systems, control is often an emergent function

68 (McClelland et al., 2010; Hofstadter, 1985, Ch. 25; Mitchell, 2009).

69
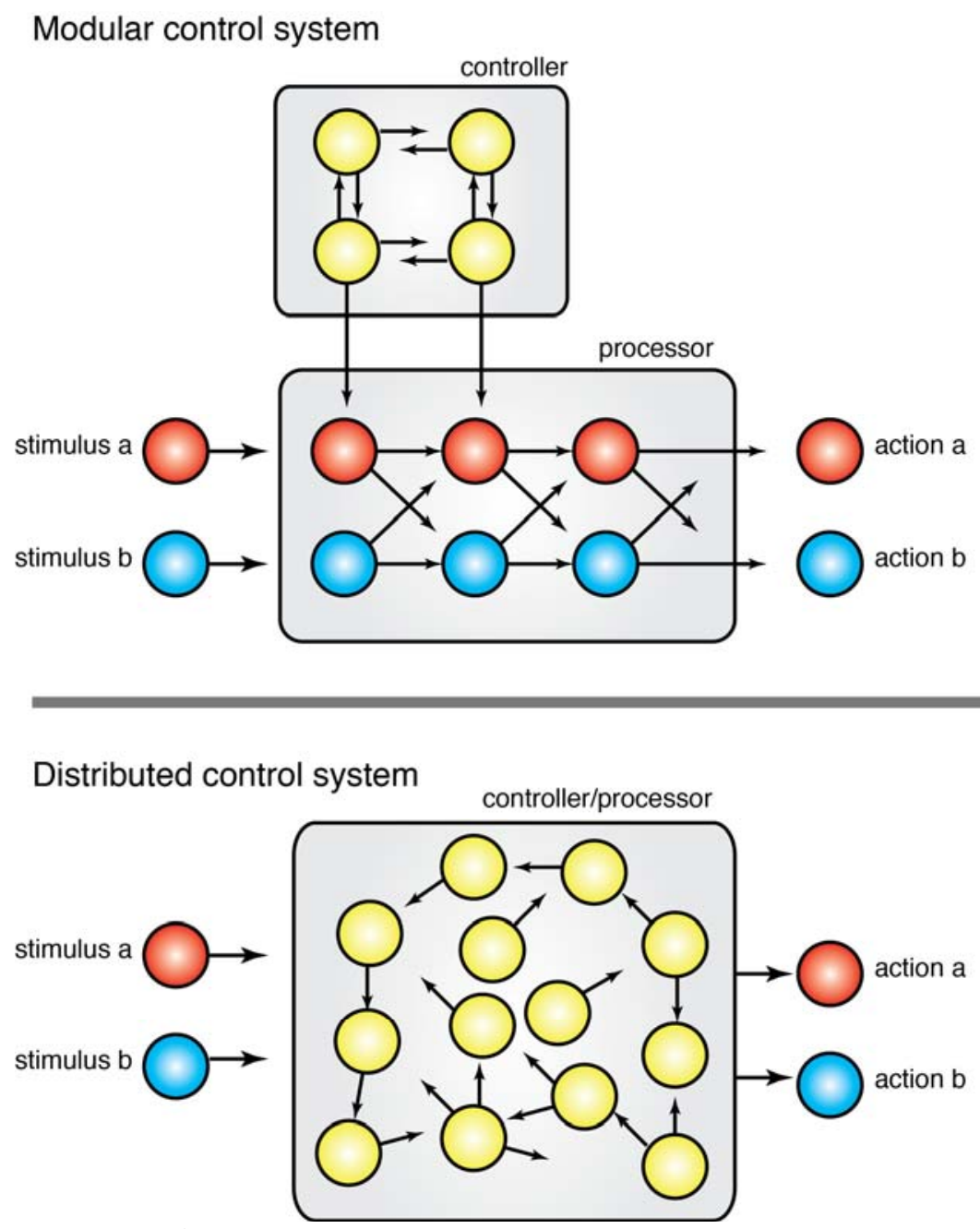

Figure 1. Contrasting organizations of modular and distributed control systems. Within modular control systems, processing and control elements are distinct and localized to specific areas. By contrast distributed systems combine control and processing elements, often into individual agents.

The distributed viewpoint derives inspiration from early studies on cybernetic, connectionist, and parallel distributed processing models (Rummelhart et al., 1988; Weiner et al., 1944; Grossberg, 1974; Hopfield, 1982). As noted in a review of the topic by Botvinick and Cohen (2014), the connectionist heyday of the late 70's and early 80's coincided with the development of formal ideas of control (Posner \& Snyder, 1975; Shiffrin \& Schneider, 1977; Norman \& Shalice, 1986; Baddeley \& Hitch, 1974). It is ironic then that almost all models of executive control, even relevant PDP models, take as given that control is functionally and anatomically modular (Botvinick \& Cohen, 2014). Nonetheless, history has vindicated this approach: the modular idea is well supported by 
empirical data. Specifically, neuroscientific research consistently points to dorsal prefrontal structures (especially the dorsal anterior cingulate cortex, dACC, see below), as well as superior parietal cortex and parts of the brainstem as the brain's control system (Holroyd \& Coles, 2002; Botvinick \& Cohen, 2014; Ridderinkoff et al., 2004; Shenhav, Botvinick \& Cohen, 2013; Miller \& Cohen, 2001; Sleezer \& Hayden, 2016; Floresco, 2015; Mansouri et al., 2007).

\section{Revisiting the distributed processing view}

Still, we believe that it is time to revisit a distributed approach to control. Several factors motivate this belief. First, our understanding of the neuronal (i.e. single unit) responses of the putative executive regions is only now maturating. Some of this work emphasizes the broad overlap in functions of the prefrontal and posterior regions; these functions appear to include both processing and executive roles (Cisek \& Kalaska 2010; Kim \& Shadlen, 1999; Chafee \& Goldman-Rakic, 1998; Postle, 2006; Awh \& Jonides, 2001; Sleezer \& Hayden, 2016a; Sleezer, Castagno, \& Hayden, 2016). Second, new anatomical and functional techniques emphasize the fundamentally non-modular organization of the brain (Misic \& Sporns, 2016; Wang et al., 2015; Farah, 1994; Kristan \& Shaw, 1997; Plaut, 1995). Third, major recent advances in computation have come from abandoning classic (GOFAI)-style symbol manipulating systems in favor of deep learning algorithms that are distributed and recurrent (e.g. Lecun, Bengio, \& Hinton, 2015; Hinton \& Salakhutdinov, 2006). These approaches highlight the power and flexibility of non-modular network organizations. Finally, recent years have seen a greater understanding of the mechanisms of distributed control in non-brain biological systems, leading to a greater appreciation of the strengths and of the biological plausibility of such systems (Couzin, 2009; Passino, Seeley, \&Vischer; 2007).

Reified models of executive control - in which conceptual elements like monitor, controller, and processor have direct correspondence with neuroanatomy - are intuitive. But distributed models are less so. To mitigate this problem here we offer a summary of the basic principles of distributed control systems, with an emphasis on natural examples.

\section{Principles of distributed control systems}

\section{Principle 1: Horizontal information flow}

Within a modular control system, information flows linearly from lower level processing units to the controller. By contrast information flow within distributed systems is characterized by horizontal communication between adjacent members. In other words, information is derived from neighbors, not from a central communicator. Consequently, no single member of a distributed system is knowledgeable about the entire system. Each member can know what their neighbor is doing, and possibly what their neighbor knows, through localized interactions.

A good example of information flow within a distributed system is a herd of baboons on the move (Papio anubis, Couzin \&Krause, 2003; Strandberg et al, 2015). Even though they have a hierarchical dominance system, no single member of the troop knows for sure where to go but several members have some limited and likely noisy knowledge (Figure 2). The wisdom of the crowd is better than any individual's guess, as in many collectively moving animals - including humans (Codling, Pitchford, \& 
132 Simpson, 2007; Simons, 2004; Hamilton, 1967; Bergman \& Donner, 1964; Walraff,

133 1978; Mallon, Pratt, \& Franks, 2001; Conradt \& Roper 2003). The baboon troop thus

134 uses a collective decision-making strategy. Individuals begin to head off towards their

135 best guess and as they do this, troop members compute the average of the members they

136 observe. Unlike in a modular system each member may be simultaneously a decision

137 maker and a data point for other decision makers.

138 Normally this strategy leads efficiently to a rapid consensus (Couzin \& Krause,

139 2003; Conradt \& Roper, 2003). In cases where there are two different modal preferences

140 - say, when northeast and northwest are both good directions but true north is not, this

141 averaging strategy leads to a suboptimal choice (Figure 2B). For this reason individuals

142 should be - and are - sensitive to bimodal distributions among the group and, in that case,

143 randomly choose one of the two modal directions (Strandberg et al, 2015). Similar

144 patterns are observed in pigeons and human crowds (Biro et al., 2006; Dyer et al, 2008).

145 In this example, the input is the environmental clues (including memories) about the

146 best direction to head and the output is a group path. Information is distributed across

147 individual troop members who communicate locally with each other. Drawing from the

148 local interactions among members, the group chooses a better output than all the

149 constituent individuals. The decision is also controlled in a closed-loop manner: the

150

151

152

153

154

155

156

157

158

159

160

161

162

163

164 group can monitor its own performance (it can detect split voting) and regulate its voting strategy (averaging to bifurcation-then-averaging), even though no individual serves as the specialized monitor or regulator. Instead, monitoring and control proceed through local, horizontal connections between members.

The idea of horizontal flow of information from adjacent members is also often a description of neuroanatomical organization. Neurons, like troop members, tend to have limited view of the activity of the whole, limited ability to communicate with the whole, incomplete information, no knowledge of the larger factors that determine the group's well-being, and no obvious leadership. However, neurons do have a rich network of connections to adjacent neighbors and cortical areas that supports a localized flow of information. While the brain also has centralized global signaling, in the form of neuromodulators (and possibly cortical oscillations), the bandwidth of these signals is limited and the timing may be too slow to affect on-line decision processes. Similar to a baboon troop, the information gained from equal and adjacent members has a large effect on the regulation of its neural function. 
166

167

168

169

170

171

172

173

174

175

176

177

178

179

180

181

182

183

184

185

186

187

188

189

190

191

\section{A}

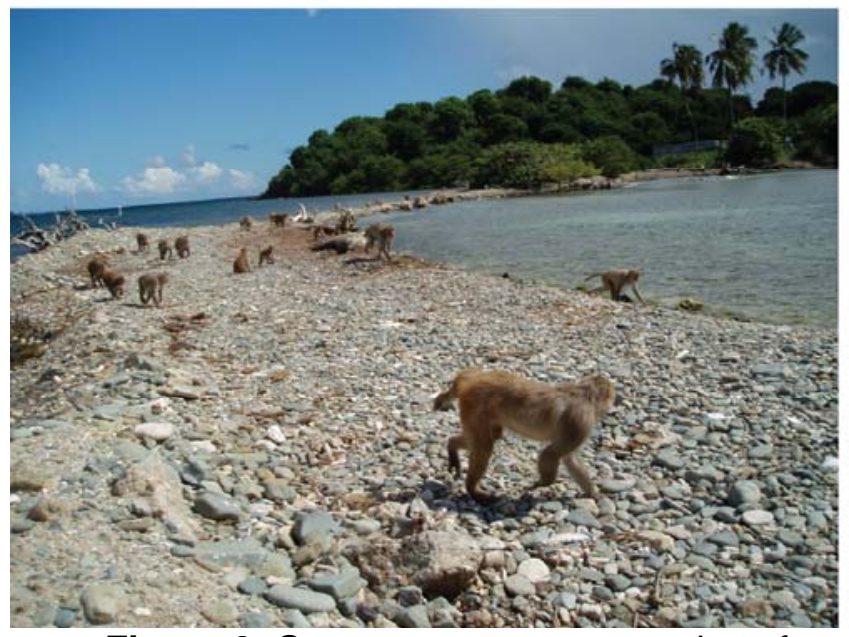

Figure 2. Group movement strategies often illustrate the principle of horizontal information transfer. A. Rhesus monkey troops on Cayo Santiago migrate multiple times each day and may use distributed consensus procedures to choose a direction. B. Cartoon birds eye view illustrating split voting situation. If the troop is split between a northeast and a northwest direction, the consensus will not be the average (north) but one of the two modal directions.

\section{Principle 2: Stigmergy}

In the case of the baboons, it is notable that the control signal is the movement of neighbors. Thus, in a strongly non-modular way, the control signal is precisely the output of the underlying process (also movement of individuals). It is a stigmergic system (Bonabeau, Dorigo, \& Theraulaz, 1999; Theraulaz, Bonabeau, \& Deneubourg, 1998; Couzin, 2009).

A familiar example of stigmergic signaling is lawn shortcut generation on college campuses. A student following the trod path also - weakly but surely - strengthens it (Figure 3.). Another example is pheromonal trails in foraging ants (Hölldobbler \& Wilson, 1990; Wilson, 1971). As a scout forages she lays a scent that other scouts will follow to valuable food sources. The scent evaporates quickly, so rich food patches, which attract many ants, will have stronger paths leading to them. An ant that, by chance, discovers a shortcut will produce a trail with a stronger scent (because, being shorter, it takes less time to traverse and thus has more scent, Beckers \& Deneubourg, 1992). In this way, pheromones allow ant colonies to find rich food sources and develop shortest path routes without any centralized control (Aron, Beckers, \& Deneubourg, 1993; Jackson \& Chaline, 2007; Beekman, Sumpter, \& Ratnieks, 2001). 


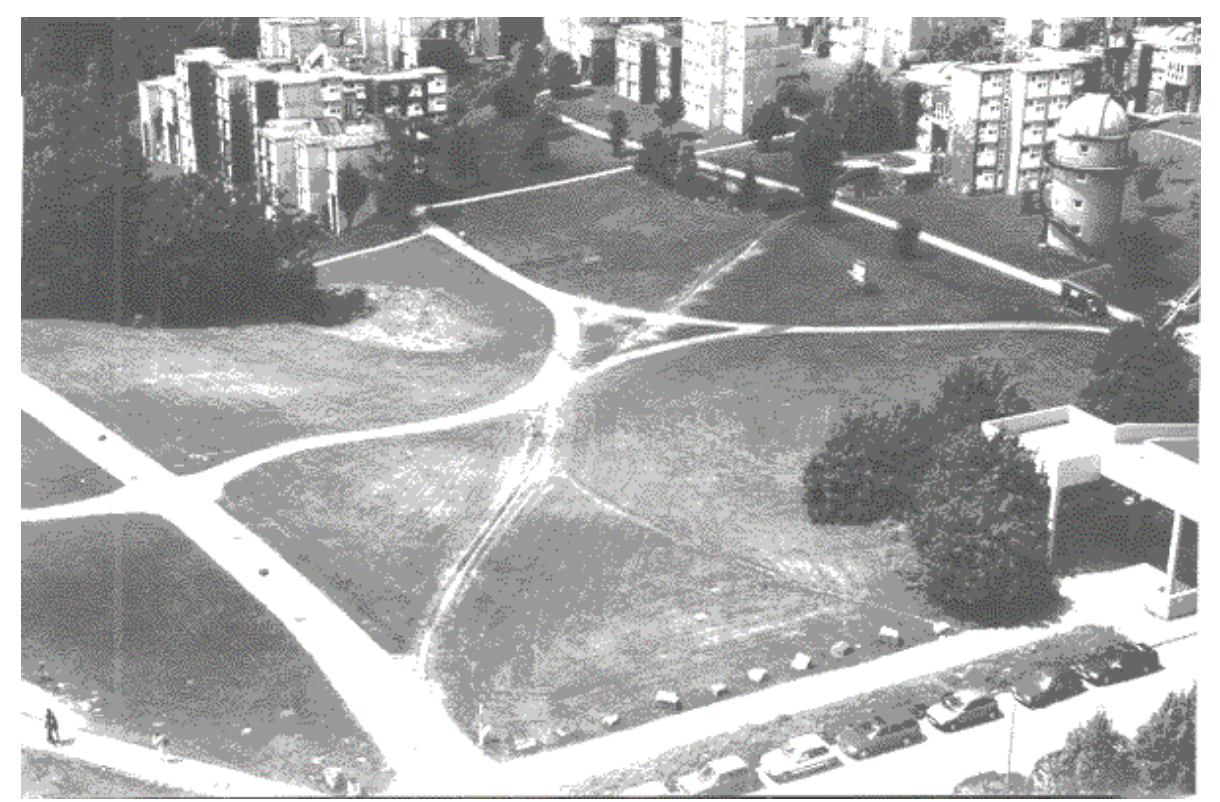

Figure 3. Humans can collectively identify, create, and maintain efficient paths across lawns on college campuses. Reproduced with permission from "Modeling the evolution of human trail systems" (Helbing, Keltsch, \& Molnar, 1997).

Another example of stigmergic control comes from the process of neural differentiation of sensory organ precursors within the developing fly brain (Drosphilia melanogaster) (Navalakha \& Bar-Joseph, 2011). During development some cells within the neural clusters of the fly brain become sensory organ precursors (SOPs); these cells form the backbone of the sensory system later in development. Determination of which cells become SOPs follows an algorithmic process that produces a maximally independent set distributed throughout the brain. Functionally each cell will propose itself as a possible SOP. If any neighboring cell has already become a SOP the proposing cell will not differentiate. As a consequence of this process the likelihood of an unconnected cell differentiating increases with time (Afek et al., 2011; Navalakha \& Bar-Joseph, 2011). By using information about the structure of neighboring cells, each cell is able to differentiate appropriately so that the whole brain achieves an equal spacing of sensory organ precursors. The brain cells do this rapidly and without the need for a monitor or knowledgeable controller sending distinct control signals. All the monitoring and control that is needed occurs locally, within each cell.

Principles of stigmergy within executive control processes relates to neural function quite directly. Neurons produce chemical outputs that modulate responses of downstream neurons. These outputs are both the computational outputs of the neurons and a way to modulate activity of their neighbors. In the short term, excitatory and inhibitory outputs increase and reduce, respectively, the likelihood that the target will fire. In the long term, activity (especially coincident activity) promotes synaptic plasticity thus up- or downregulating that target's firing on longer timescales. Within cortical regions, these localized interactions could very well lead to emergent control signals without the need for a dedicated controller (Couzin, 2009).

\section{Principle 3: Feedback loops}


Feedback is a powerful tool in any dynamical system. It can have positive effects. When fish school, a few peripheral individuals may detect a potential predator and turn away from it (Treherne \& Foster, 1981; Couzin \& Krause, 2003). Neighbors who follow an average-direction rule then turn and also affect their neighbors, the effect multiplies, and the traveling wave of turning fish turns the whole school away. The amplification protects many more fish than were able to detect the predator. Similarly, feedback loops are a mainstay of other distributed leaderless systems; even audience clapping, for example, can depend on feedback effects (Néda et al., 2000)

However, feedback loops can be dangerous as well (Giraldeau \& Valone, 2002). Simple effects can snowball and, because the system is distributed, there is no central controller to stop it. For example, ants leaving a pheromonal trace can find their own trail, and start going in a circle - a literal feedback loop called an ant mill (Delsuc, 2003). Another important example of a feedback loop is a marketplace bubble (Porter \& Smith, 1994; Smith, Suchanek, \& Williams, 1988). If a speculator believes a commodity will go up in price, she may bid a slightly greater price than the current one. This bidding will serve as a signal to other investors that the commodity may be a wise investment. As they bid up the price, their initial assessment will be proven to be right, and other investors will gain interest. This pattern can lead to runaway prices, but only up to a point; as soon as this point is reached, the price will crash.

The tendency to boom and bust can lead to market instability and to underinvestment. In marketplaces, centralized control (such as trading limits) can solve these problems. Without that kind of control, avoiding these kinds of malign feedback loops requires careful calibration of the rules each individual follows. Such calibrations often involve complementary negative feedback loops (Grünbaum, 1998). The analogy to brains, which have many overlapping positive and negative feedback loops, is quite direct.

\section{Principle 4: Self-organization through simple rules}

Many distributed control systems are self-organized (Sumpter, 2006). Classic examples of self-organization include bird flocks and fish schools (Aoki, 1982; Couzin, 2009; Reynolds, 1987). No leader bird rallies its mates and tells them where to fly; nor does a leader monitor the flock and guide its performance like coxswain on a crew team. Instead, the structure of the bird flock is a consequence of several simple principles followed by all individuals. These include rules about distance between adjacent birds (not too far and not too close, more or less) and rules about when to turn (follow the group average, Couzin $\&$ Krause, 2003). The specific rules, not a leader-bird, determine the shape of the flock (Figure 4). 
260

261

262

263

264

265

266

267

268

269

270

271

272

273

274

275

276

277

278

279

280

281

282

283

284

285

286

287

288

289

290

291

292

293

294

295

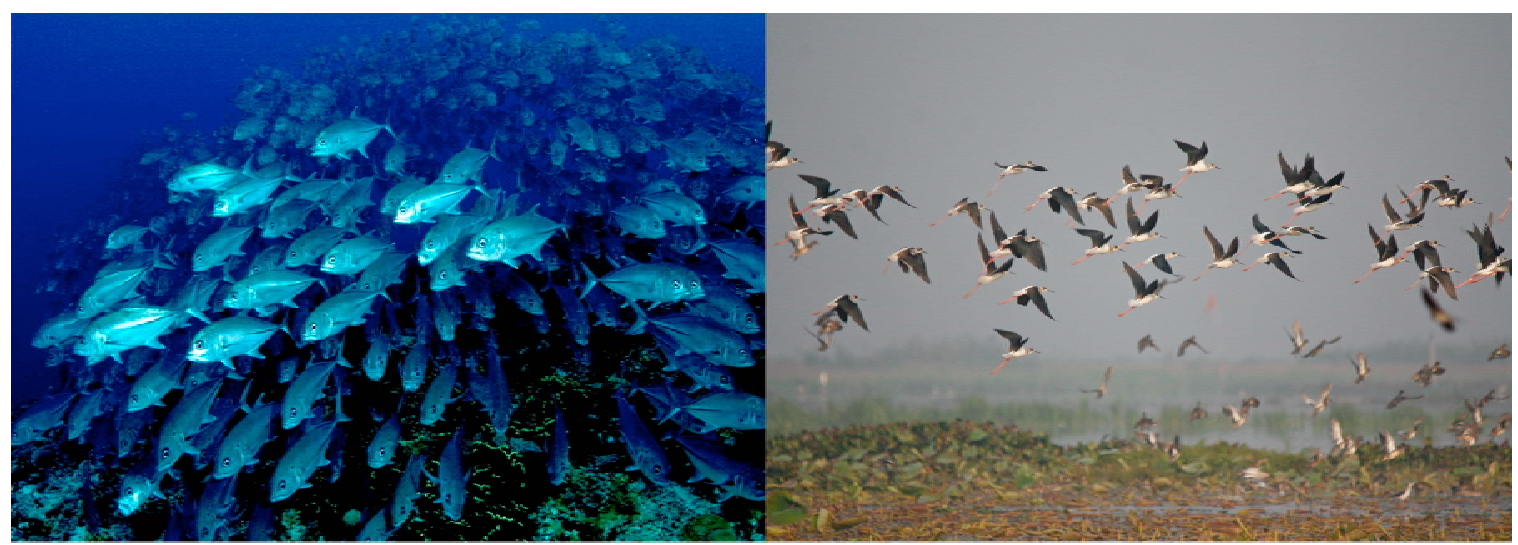

Figure 4. Simple rules of distance and spacing determine the shapes of both fish schools and bird flocks. [Fish picture: Gordon Firestein - Seacology USA, Bird Flock: Faisal Akram]

Self-organization is an appealing principle because it is easy to implement and is robust to degradation (Sumpter, 2006). In contrast, the centralized systems are vulnerable to the loss of the controller: Remove a switch and the whole railyard breaks down; remove the coxswain and the rowers start hitting each other's oars; remove one bird and the flock swiftly adjusts. Self-organization also allows complex adaptive behavior without programming expensive control systems. Self-organized systems can be "fast, cheap, and out of control" (Brooks \& Flynn, 1989). These features - ease of implementation, graceful degradation, and robustness, makes it appealing for analyzing neural systems. One well-known example of a self-organizing system in neurons is central pattern generators, in which the activity of the ensemble is an emergent product of the interactions of the elements, none of which follows the pattern in miniature.

This does not mean all distributed systems are leaderless. There are many contexts in which formation of leadership is favored (Couzin et al., 2005; Fischoff et al., 2007; Dyer, 2009; Robson \& Traniello, 1999; Reebs, 2000). Dominance hierarchies and other leadership structures are selected in many species, although leadership is seldom absolute. And there are intermediate cases - even in the case of baboons, some individuals are recognized as having greater knowledge of the right path and their opinion is more highly weighted (Strandburg et al., 2015).

Presumably, we can classify control systems on a spectrum from fully distributed and leaderless to strictly segregated and hierarchical; the specific organization observed for any system will depend on the environment in which it evolved. This fact is important to remember when considering neural systems, which may have some specialization of function (Botvinick et al., 2001; Rougier et al., 2005; Kanwisher, Mcdermott, \& Chun, 1997).

\section{Principle 5: Quorum-sensing}

Agents in distributed systems have very limited field of view in their monitoring capabilities. In other words, it is often difficult to see the forest for the trees. But sometimes it is critical to see the forest to make the best decision. In these cases, agents must engage in quorum-sensing: a type of consensus-based control mechanism wherein a set threshold or quorum determines the course of action (Mitchell, 2009). 
296

297

298

299

300

301

302

303

304

305

306

307

308

309

310

311

312

313

314

315

316

317

318

319

320

321

322

323

324

325

326

327

328

329

330

331

332

333

334

335

336

337

338

339

340

341
There are many mechanisms for quorum-sensing; what unites them is that they do not require centralized control. For example, bacteria can produce diffusible chemicals (which can serve as a type information) and chemical concentration in the environment gives a measure of quorum (Waters and Bassler, 2005). One critical feature of any consensus-seeking measure is that it must terminate; it should also do so relatively quickly. Failures to do so can be costly, as in the case of Buridan's ass (Lindauer, 1957; Pais et al., 2013).

Often, individuals can sense the state of conspecifics in their local environment and extrapolate to an estimate of group state. Simply averaging the states of neighbors can be helpful in some circumstances, as in bird flocks and some fish schools. One study showed that an individual schooling three-spine stickleback fish (Gasterosteus aculeatus) can adopt a non-linear monitoring function that produces better group behavior emergently (Ward et al., 2008). Specifically, groups of fish tended to ignore information from single neighbor but responded when two fish conveyed the same information. This non-linear criterion can reduce the probability of amplifying noise but can still effectively detect signals.

The need for agents to sense the properties of the whole, or of large subgroups, is a major problem in brain systems as a whole. This problem is acute in executive control systems, which often rely on changing processing as a function of global conditions. Without holistic integrating neurons, it is difficult to imagine a direct solution to the problem. For this reason, studies of quorum-sensing systems, which solve the problem indirectly, are particularly likely to be helpful in understanding the neural basis of control.

\section{Distributed solutions to classic executive control problems}

Studies of executive control tend to focus on processes for solving a familiar set of cognitive problems. Prominent among these processes are regulation of stop/go behavior, speed/accuracy tradeoffs and conflict detection and resolution (Bogacz et al., 2009; Aron, Robbins, \& Poldrack, 2014; Botvinick et al., 1999; Miller \& Cohen, 2001). These operations have analogues outside of neuroscience, including in distributed control systems of natural and artificial mechanisms. In this section, we investigate how some examples of distributed control systems handle these executive control problems through the fundamental elements outlined above. Other important executive functions, which we do not consider, include working memory, attention, task set maintenance and switching, regulating the balance of explore vs. exploit behavior, and aspects of reinforcement learning. Several of these have likely correlates in distributed control systems as well. See, for example, (Couzin et al., 2002; Couzin, 2009; and Passino, Seeley, \& Visscher, 2007) for speculation about how distributed processing systems can implement working memory, attention, and regulation of long-term memories.

\section{Stopping and going: Vibrio fischeri bacteria}

Initiation and inhibition of behavior is a simple and important executive function (Jin \& Costa, 2010; Schall, 2001; Aron, Robbins, \& Poldrack, 2004; Niv et al., 2007; Hampshire \& Sharp, 2015; Kacelnik et al., 2011). Coordination of these two antagonistic processes can produce both simple responses and complex behaviors. Stop/go behavior 
342 involves elements like precise timing, inhibition of prepotent responses, and control of

343 vigor. Another important but less well-appreciated requirement is avoiding intermediate

344 responses, so that the system can either fully stop or fully go, without drifting between

345 the two extremes. In other words, being indeterminate can be costly and even lethal in

346 urgent situations so that the distributed system has to be able to deal with this problem.

347 Our example of stop/go control in a distributed control system comes from the

348 luminous bacterium Vibrio fischeri (Waters \& Bassler, 2005; Nealson \& Hastings, 1979;

349 Miller \& Bassler, 2001). This single-celled organism lives in the light organ of the

350 Hawaiian bobtail squid (Euprymna scolopes) and emits light when the squid hunts at

351 night. The light serves to camouflage the squid that otherwise would be visible in the

352 form of a moonlit silhouette to prey below it (Visick et al., 2000). During the day the

353 squid hides from potential predators in the dirt and turns its eyes off by extruding most of

354 the bacteria into the surrounding ocean. As the day progresses the remaining bacteria

355 reproduce rapidly, and, by nightfall, have replenished their stock so that there are enough

356 bacteria to serve as an effective camouflage.

357 The control problem comes from the fact that the bacteria must not luminesce

358 during the day as they are reproducing. Instead they need to switch to lighting at night all

359 at once. In other words, bioluminescence needs to be both inducible and repressible

360 (Nealson \& Hastings, 1979). Because of their reproduction pattern, they can do this by

361 waiting until there is a quorum of other $V$. fischeri bacteria in the squid light organ. But

362 how do they know how many others there are? Quorum sensing. V. fischeri release a

363 chemical known as acyl-homoserine lactone (AHL). They then measure the concentration

364 of this chemical in their local environment by the transcription activator protein LuxR,

365 which creates a complex that induces transcription of genes needed for luminescence

366 (Kaplan \& Greenberg, 1985; Stevens \& Dolan, 1994). The transcription process is only

367 triggered when the local density of AHL reaches a predetermined threshold, which serves

368 as a go signal for the bacteria (Figure 5).

369 


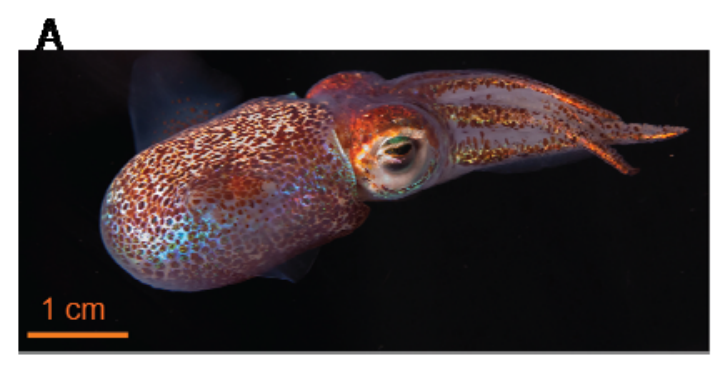

B
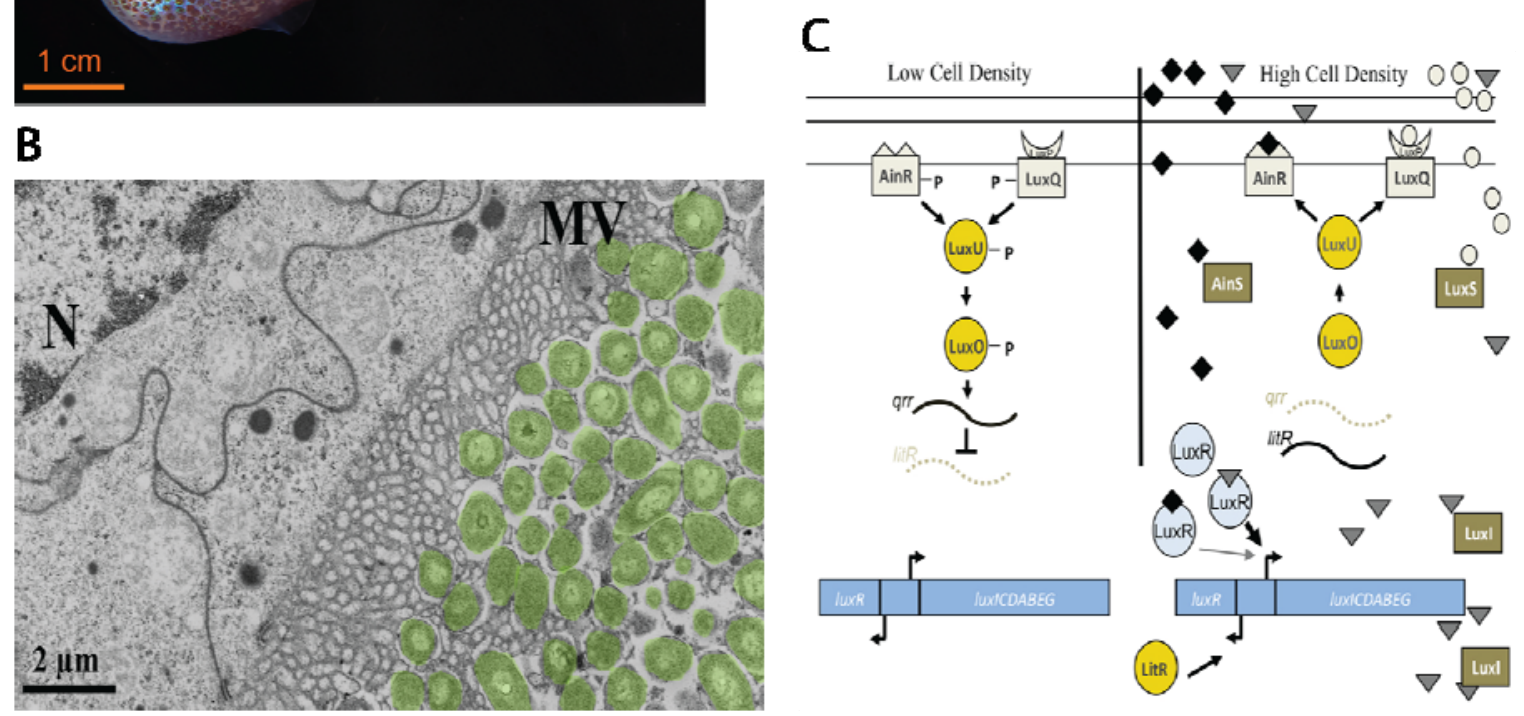

Figure 5. A. Hawaiian squid (Euprymna scolopes). B. Image of $V$. fischeri embedding into microvilli of host epithelial cells. C. Illustration of control circuit for regulation of luminescence through chemical detection in $V$. fischeri. Credits: $(A, B)$ reproduced with permission from "Divining the essence of symbiosis: Insights from the squid-vibrio model." (McFall-Ngai, 2014). (C) reproduced with permission from "Gimme shelter: how vibrio fischeri successfully navigates an animals multiple environments" (Norsworthy \& Visick, 2013).

There are several features used by the system to stop, i.e. to prevent premature luminescence. These features work by implementing negative feedback (Waters \& Bassler, 2005). One feature is regulation of the stability of the constituent proteins: they are more stable when AHL is more concentrated (Zhu \& Winans, 1999). Another is active pumping of AHL out of the cell: this process reduces cytoplasmic levels of AHL and thus dampens sensitivity until AHL concentration is high enough to overwhelm the pumping mechanism (Pearson et al., 1999).

Several features of this stop/go process are notable here for the curious neuroscientist. First, the system implements a clock-like function by taking advantage of the consistency in reproduction rates of its own members. No member or subgroup serves as a clock or other timer function. In other words, the timing function is an emergent property of the system. Second, there is no centralized site that tells the bacteria when to glow; each individual agent makes up its own tiny mind, but, because they are in the same environment, their activity is effectively coordinated through the localized crosssignaling of individual cells. Third, the system implements a specific and precise threshold-crossing process (a simple rule based on concentration levels of AHL), even though no abstract decision variable is calculated or represented. Finally, there is no need for any kind of modular self-control or inhibition. The lack of glowing (repressability) is 
397

398

399

400

401

402

403

404

405

406

407

408

409

410

411

412

413

414

415

416

417

418

419

420

421

422

423

424

425

426

427

428

429

430

431

432

433

434

435

436

437

438

439

440

441

442

simply a consequence of the fact that there are insufficient concentrations of chemicals to drive the glowing; inhibition in this system is an emergent process (cf. Hampshire \& Sharp, 2015).

\section{Speed-accuracy tradeoffs: ants}

A decision made without taking the time to gather all the evidence may not be as accurate as a deliberate one, but it will have the virtue of speed (Houston, Kacelnik, \& McNamara, 1982). If time is costly (as when faced by an attacking predator) it may be worth going for the first good response, but if the decision-maker has all the time in the world, it's probably worth doing some pondering. Speed-accuracy tradeoffs are a staple of cognitive psychology (Busemeyer \& Townsend, 1993; Wickelgren, 1977; Roitman \& Shadlen, 2002; Chittka et al., 2003; Gigerenzer \& Goldstein, 1996; Bogacz et al., 2010) and animal psychology (Chittka, Skorupski, \& Raine, 2009). Like humans and animals, many distributed decision-making systems make speed-accuracy tradeoffs, including slime molds (Physarum polycephalum) and honeybees (Apis mellifera, Dussutour, Latty, \& Beekman, 2010; Passino, Seeley, \& Visscher 2007).

When looking for a new nest, individual ants (Leptothorax albipennis) leave the nest and evaluate potential locations within a few square meters (Franks et al., 2002; Franks et al., 2003). These ants prefer to live in small colonies in thin cracks in rocks and are therefore easy to study in laboratory conditions (Franks et al., 2002). An ant that finds a potential nest site will recruit other ants to evaluate it by leading a tandem run back to the site. Thus, each site is evaluated by a large number of individuals, each of whom presumably makes a worse (less accurate) decision than the cumulative choice of several ants. Unlike bees (see below) individual ants appear to evaluate and compare multiple sites, giving them more individual knowledge and requiring smaller quorum sizes (Franks et al., 2002; Pratt et al., 2002; Franks et al., 2003). If enough ants appear at a single site, scouts recognize a quorum, and the quorum catalyzes a change in their behavior; scouts now carry their nestmates to the new site and deposit them there (Pratt et al., 2002; Franks et al., 2002).

This whole search and quorum-sense process is slow but accurate. But if the situation calls for a fast decision (such as during windy weather or threat of predation), the ant colony can make a speed-accuracy tradeoff (Franks et al., 2003). Specifically, each ant can reduce the threshold it uses to decide whether to switch from tandem run recruitment mode to carrying mode. The tandem run, being slower, allows other ants more time to discover other sites; the carry terminates the process more quickly. The ant itself doesn't know explicitly about the speed-accuracy tradeoff; it just has an internal sense of weather and adjusts its quorum-sensing procedure - and the group's speedaccuracy tradeoff is an emergent consequence (Franks et al., 2003).

The neuroscience of the speed-accuracy tradeoff is not fully understood, but the parallels are easy to discern. It is believed that there is a threshold integration process for perceptual decisions (Bogacz et al., 2010). Recent work suggests it may involve changes in the baseline activity of neurons that serve as cortical integrators that bring them closer to threshold (Ivanoff, Branning, \& Marois, 2008; VanVeen, Krug, \& Carter, 2008), perhaps through disinhibition (Forstmann et al., 2008). Complementary research suggests that slower decisions involve inhibition from the subthalamic nucleus (Frank, Scheres, \& Sherman, 2007; Aron \& Poldrack, 2006). In either case, neurons encode a decision 
443 variable that, in a distributed manner, represents the evidence in favor of the decision.

444 While these models are not strictly distributed control models (because the thresholding

445 is assumed to be separate from the accumulation), they have characteristics of it. A major

446 goal of the stopping literature is to identify the key brain site that regulates stopping. The

447 distributed control approach cautions that such a site may need not exist; instead of a site,

448 there might be a neural mechanism at work, one that is not distinct from the sites of

449 neurons that form the perception-action stream.

450

451

452

453

454

455

456

457

458

459

460

461

462

463

464

465

466

467

468

469

470

471

472

473

474

475

\section{Conflict detection and resolution: honeybees}

Humans performing a cognitively demanding task may realize the task is harder than expected and devote more effort to it (Botvinick et al., 1999; Shenhav, Botvinick, \& Cohen, 2013). For example, in the Stroop task, a subject is asked to either read a word or name the color of ink used to display it (Stroop, 1935). Reading the word is easy, but naming the ink color, especially when the word itself is a different color, requires more cognitive control. Another form of conflict is decisional conflict, which is caused by ambivalence between two equally desired options (Cai \& Padoa-Schioppa, 2012 ; Hayden, Heilbronner, \& Pearson, 2011; Strait, Blanchard, \& Hayden, 2014; Amiez, Joseph, and Procyk, 2006). Modular models of conflict detection and resolution generally involve a discrete conflict detector and resolver, which are often located in the dorsal anterior cingulate cortex (dACC, Botvinick et al., 1999, Shenhav, Botvinick, \& Cohen, 2013; Botvinick et al., 2001). We hasten to note that such models, especially with regard to dACC, are contentious: the signal may not be conflict per se, but in either case, it may regulate control, which is our interest here (Kolling et al., 2016; Shenhav et al., 2016; Ebitz \& Platt, 2015).

In springtime, thriving honeybee beehives reproduce. Roughly a third of the hive's members remain at the hive site and the others leave to form a swarm that gathers in one location and, in a few days, chooses a new hive site from a radius of several kilometers (Seeley, 2010; Seeley \& Burhman, 1999; Camazine et al., 1999). Like our ants above, scouts evaluate promising nearby sites and then return and signal their quality with special dances (Figure 7). Dances indicating higher quality sites induce other bees to investigate the same site. When scouts detect a quorum of bees at a site (typically around 20 ), they then return and provide a different signal, one that initiates a selection of the

476 hive site by the swarm (Seeley, 2010; Seeley\& Buhrman, 1999). 
A

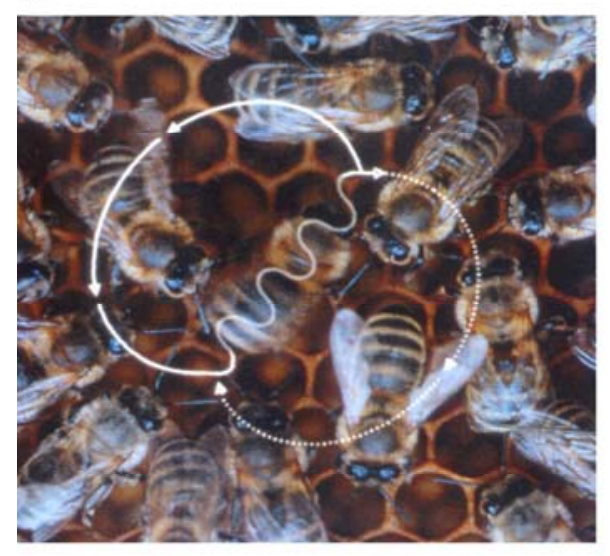

B

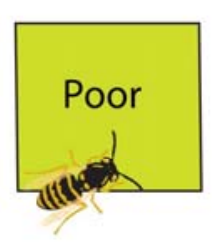

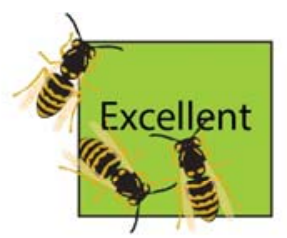

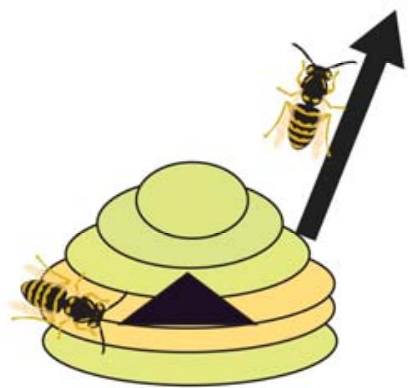

477

478

479

480

481

482

483

484

485

486

487

488

489

490

491

492

493

494

495

496

497

498

499

500

501

502

503

504

505

506

507

508

509

510
Figure 7. A) Image of honeybee waggle dance communication in a hive. Reproduced with permission from "Dances as a window into insect perception" (Chittka, 2004). B) Illustration of binary choice between hive sites. Through quorum sensing by scouts at potential nest cites and waggle dance communication with the swarm, new hive locations are efficiently chosen.

If there is one obvious best site, the decision will proceed quickly. But if there are two or more sites of approximately equal quality, the decision will proceed more slowly as the bees take the time to choose the best one. The swarm therefore is sensitive to decisional conflict: it monitors its own level of decisional ambivalence as the decision proceeds. Note that this is conflict signal a swarm, not individual variable; after all, no bee knows about more than one site, so no bee is conflicted. By not halting the search process, the swarm effectively recruits more processing resources (i.e. more bee-search time) when conflict is high. As in mental effort, deliberation is not free; swarms are vulnerable to weather and predators so there is an opportunity cost to delaying the construction of the hive (Lindauer, 1957).

Notably, the detection and resolution of conflict are emergent phenomena. No single bee that is sensitive to the conflict level - we know the rules the bees follow and none of them deal with conflict. Nor is there a conflict signal represented in the bee's waggle dance or at any other point in the system. No bee has a specialized role before the swarm starts swarming. Still, the swarm as a whole is quite sensitive to decisional conflict and able to deal with it efficiently. It's also worth noting that an aggregate measure of hive activity, say, the number of active scouts or number of active dances during the decision, will show clear and strong aggregate conflict signals. This finding is intriguing because conflict signals are seldom observed in the activity of single neurons, and yet are robustly observed in the brain's hemodynamic activity (see below).

\section{Part IV. Evidence for distributed executive control in the brain}

We turn now to the neuroscience of control. As noted above, there is a broad consensus that executive control is modular, not distributed (Botvinick \& Cohen, 2014). We believe that one reason for relative unpopularity of distributed control systems by scholars is that they are unfamiliar and unintuitive. Indeed, distributed control is 
511 notoriously difficult for us to intuit. Terms like the "ghost in the machine," "the invisible

512 hand of the marketplace," "asking the hive mind" are reminders that our own minds

513 naturally impute discrete and coherent agency even when dealing with mindless and

514 ghostless distributed systems. Still, many distributed control systems are intuitive and can

515 become more so with familiarity.

516

517

518

519

520

521

522

523

524

525

526

527

528

529

530

531

532

533

534

535

536

537

538

539

540

\section{Neuroscience methods make modularity easier to find}

Another factor disfavoring distributed control models is that the major methods for studying executive control, lesion, neuroimaging, and single unit recording, all arguably have some bias towards finding evidence of modularity.

Neuroimaging, like lesion studies, measures aggregate function of a given brain area or voxel, and thus cannot determine properties of the individual agents of the nervous system, neurons. This is true for multi-voxel pattern analysis as well as for ROItype analyses. By aggregating signals across voxels, neuroimagers lose information about activity of individual neurons. The aggregate signal in turn misses information about the specific types of local, horizontal, and narrow-bandwidth signals that are crucial for distributed systems. But it is very good at detecting even weak signals at a broad range, meaning it can readily measure emergent properties of neural populations. The limitations of the lesion method are illustrated in a study by Plaut (1995). In this work, he shows how even the double dissociation, the gold standard of lesion studies, is susceptible to false positives supporting a modular view given certain reasonable assumptions about distributed network implementations of cognitive functions.

Single unit physiology studies are just as limited, although in the opposite way. Neurons may function much like agents, but the power of distributed systems comes in the specific local interactions of small numbers of agents. Physiology can measure the activity of only one neuron at a time; even multi-cellular methods have difficulty capturing interacting neurons. Moreover, most studies focus on a single brain region with the cost of inability to measure function at the level of the interregional network.

Historically, Karl Lashley had difficulty in finding the locus of memory function by lesion techniques (Lashley, 1929). This may have been because lesions to distributed

541

542

543

544

545

546

547

548

549

550 systems do not selectively impair discrete functions, but instead have complex and unpredictable effects (Farah, 2004). Lashley found that degradation of behavioral performance depended on the amount of the brain regions removed independent of the precise location: they characteristically led to graceful degradation, which he interpreted as the product of mass action (Lashley, 1929). But when there is even a moderate amount of specialization in the system, they can lead to moderate but measurable effects. The interpretation of these effects, however, will be influenced by the experimenter's theoretical framework.

551

552

553

554

555

556

\section{A case study: the $\mathrm{dACC}$}

To look at these general issues in detail, we will take the dorsal anterior cingulate (dACC, often just ACC) as a case study. The dACC is part of the cingulum, a band of cortex that wraps around the corpus callosum in the sagittal plane. The $\mathrm{dACC}$ receives a broad and diverse set of inputs that includes both limbic and cognitive regions, as well as dopamine signals, and projects to motor, premotor, and executive regions. These factors make it a natural site for serving as a monitor and controller. Indeed, a great deal of 
557

558

559

560

561

562

563

564

565

566

567

568

569

570

571

572

573

574

575

576

577

578

579

580

581

582

583

584

585

586

587

588

589

590

591

592

593

594

595

596

597

598

599

600

601

602 evidence links it to these two functions, among others. This evidence includes physiology (Heilbronner \& Hayden, 2016), neuroimaging (Ridderinkoff et al., 2004; Shenhav, Botvinick, \& Chohen, 2013; Kolling et al., 2012, Hare et al., 2011; Behrens et al., 2007; Hayden \& Heilbronner, 2014), and lesion studies ( Rudebeck et al., 2006; Kennerley et al., 2006; Picton et al., 2007; Turken \& Swick, 1999). Most prominently its responses are activated by contexts that promote control (Rushworth et al., 2011; Shenhav, Botvinick, \& Cohen, 2013). These include conflict (Botvinick et al., 19999; Ebitz \& Platt, 2015; Sheth et al., 2012; but see Kolling et al., 2016 and Ebitz \& Hayden, 2016), surprising and unexpected outcomes (Matsumoto et al., 2007; Hayden et al., 2011; Ito et al., 2003), rewards (Seo \& Lee, 2007; Hayden, Pearson, \& Platt, 2009; Kennerley et al., 2009); progression through a task (Ma et al., 2014; Shidara \& Richmond, 2002; Hayden, Pearson, \& Platt, 2011b), changes in environmental context and volatility (Behrens et al., 2007; Procyk, Tanaka, \& Joeseph, 20000; Shima \& Tanji, 1998), control of actions (Strait et al., 2016; Nakamura, Roesch, \&Olson, 2005), and others not listed here. It is also directly activated by factors related to control, such as persistence (Blanchard, Strait, \& Hayden, 2015; Chudasama et al., 2013; Parvizi et al., 2013; Hillman \& Bilkey, 2012; Hillman \& Bilkey, 2010).

These findings generally support a modular view of cognition, one in which dACC takes on the specialist role of monitor and controller. However, a broader review suggests that $\mathrm{AACC}$ is neither uniquely involved in monitoring and control, not is its function primarily these two roles. Indeed, the very long list of functions above should raise suspicion for a devotee of the modular viewpoint. Yes, these variables can all be placed under the rubric of monitoring and control, but at some point the definition becomes so elastic that it contains almost all of cognition. Second, are all these functions found only in the dACC? Unlikely. Most of these functions are shared with many other brain regions (Cisek \& Kalaska, 2010). For example, recent work points to the important of the orbital surface in classically anterior cingulate functions like conflict monitoring and resolution (Mansouri, 2014), and regulating the explore-exploit tradeoff (Blanchard et al., 2015).

Studies that compare dACC activity with other brain regions often find that differences are more qualitative than quantitative (Hokosawa et al., 2013; Kennerley et al., 2009; Azab \& Hayden, 2016). Indeed, control is associated with many other prefrontal structures, including OFC, dIPFC, vmPFC, and vlPFC (e.g. Schoenbaum et al., 2009; Wilson et al., 2014; Bechara, 2005; Buckley et al., 2009 ). Nor are these functions limited to the PFC; control signals are observed in the parietal cortex, the posterior cingulate cortex, the thalamus, and the striatum (e.g. Hayden, Smith, \& Platt, 2010).

More broadly, summaries of dACC function tend to emphasize its potentially specialized role as a hub, linking visceral, cognitive, and motor systems (Bush, Luu, \&Posner, 2000; Morecraft \& VanHoesen, 1997; Rushworth et al., 2011; Paus, 2001; Heilbronner and Hayden, 2016). But is it really all that specialized? There is anatomical and functional evidence for it's hub-nature, but it's also true of other brain regions, including, for example, PCC (Heilbronner, Hayden, \& Platt, 2011; Heilbronner \& Platt, 2013 ) and insula. Indeed, rich interconnectivity is a feature of many brain systems (Wang \& Kennedy, 2016; Heilbronner \& Haber, 2014; Heilbronner et al., 2016).

Nor are the response properties observed in the dACC uniquely control-related. Many of them seem to fit naturally into the category of stimulus-response processing, rather than as a regulator of that processing. That is, if we think of the brain as a system 
603

604

605

606

607

608

609

610

611

612

613

614

615

616

617

618

619

620

621

622

623

624

625

626

627

628

629

630

631

632

633

634

635

636

637

638

639

640

641

642

643

644

645

646

647

648

that converts sensory inputs to motor outputs, we should expect in a modular brain to find no sensory and motor signals in AACC, and instead find pure control-selective signals (Cisek, 2012). Instead, dACC is prominently responsive to both sensory stimuli and to actions. One convenient parameter to look at is spatial representation; this is a prominent property of the physical world but should, in theory, not be part of the recondite world of control. And yet dACC encodes the locations of stimuli under consideration and the specific details of actions (Hayden \& Platt, 2010; Isomura et al., 2003; Luk \& Wallis, 2009; Stoll et al., 2016? ; Strait et al., 2016; Shima \& Tanji, 1998).

Together these pieces of evidence argue that the differences between the dACC and adjacent structures are not as strong as is conventionally believed. They suggest instead a broad continuity of function between dACC and its neighbors and afferents. The broad functions, especially in the control domain, that it serves, are more distributed than modular. Moreover, the units of dACC - its neurons - appear to play a role in inputoutput processing as well as in generation of control signals. That is, from the perspective of a scientist accustomed to thinking about bee swarms and ant colonies, they look much like individual bugs: sensitive to multiple task parameters and capable of generating their own control signals, which influence their neighbors, and have the capability of participating in a larger cascade and, under the right circumstances, having effects at the aggregate level.

\section{Maybe executive control could be distributed in the brain?}

A priori, it is not unreasonable to think so. A basic description of the brain sounds like an ideal candidate for a distributed control system. Neurons are agents that can only communicate with a very small number of neighbors relative to the whole population. Like bacteria, they use a variety of diffusible chemicals to communicate. Each neuron can monitor an extremely limited portion of the world and can broadcast its signals to a very narrow part of the world as well. Each neuron has limited but powerful and nonlinear computational properties.

Moreover, each cell is autonomous, but they work together, non-competitively, in the service of a much larger goal (overcoming competition is a major barrier for many distributed systems, Sumpter, 2006). Individual neurons possess the ability to regulate the activity of other neurons (or output structures) through changes in firing rate. This activity can serve as both a processing and a regulatory role. The properties of the whole system (the brain) are rich and flexible, much more so than any of its constituents (Hofstadter, 1985, Ch. 26). The brain makes use of both positive and negative feedback, and shows slow changes over time.

Strong circumstantial evidence for the distributed view comes from lesion studies (Farah, 2004; Wilson et al., 2010). Damage has surprisingly weak and graded effects; graceful degradation is a well-known property of distributed systems (McClelland et al., 1987). Of the major "clean" effects associated with lesions (prosopagnosia, hemianopia, scotoma, and so on), few would be considered executive control effects. Instead, impairments in executive control can come from lesions in many different areas, and associated effects are generally graded, and only grow serious when the lesions become quite large(Farah, 2004; Lashley, 1929; Wilson et al., 2010).

Although there is some evidence for control-specific lesions (Shallice, 1982; Levine et al., 1998; Duncan et al., 1996), it may be difficult to pin these data clearly to control 
649 functions. Instead, it may be that more difficult processing is impaired but simpler

650 processing is spared. Consider, for example, an ant colony with a large proportion of

651 members lesioned. That colony would have no trouble choosing a hive site if the decision

652 was easy, but would have a great deal of trouble with a more difficult decision. We

653 should not then conclude that the task-difficulty module is broken.

654

655

656

657

658

659

Indeed, the brain was the original inspiration for connectionist and PDP networks.

The linkage between brain organization and other distributed control systems has been pointed out by many others before (Seeley, 2010; Couzin, 09; Passino et al., 2007;

Mitchell, 2009). Given these facts, it is striking that the distributed view has not

continued to serve as the null hypothesis for modular theories as a viable alternative view.

660

661

662

663

Methods that can push for a distributed processing view

However, recent technological advances have made the distributed processing

664

665

more attractive for researchers. With the adoption of newer analysis techniques, a host of traditional imaging methodologies are beginning to highlight the interconnectivity and coordination of many brain regions during a variety of tasks (Sporns and Betzel, 2016).

666

667

668 For example functional connectivity analysis is a growing trend in fMRI imaging studies (Sporns and Betzel, 2016; Craddock, Tungaraza, and Milham, 2015). In contrast to traditional ROI analysis, functional connectivity analysis focuses on the interaction pattern between the brain regions as the determinant of brain function rather than the activity of the single brain regions (Craddock, Tungaraza, and Milham, 2015; Sporns,

671

672

673 Tononi, and Kotter, 2005). Likewise, an increasing emphasis on large-scale brain networks has lead to a revision of cognitive functions extending across modular boundaries and sparked efforts to define functional regions based on "connectional fingerprints" (Misic \& Sporns, 2016; Passingham, Stephan, \& Kotter, 2002). These

675

676

677

678

679 trends have lead to the new field of network analysis and connectomics that emphasizes the interconnections of different brain regions across structure and function. A recurrent theme in many studies utilizing network analysis is the distributed processing nature inherent to many tasks across brain regions over a singular key region (Wang et al., 2015; Bressler \& Menon, 2010).

680

681

682

683

684

685

686

687

688

689

690

691

692

693

The modular vs. distributed debate in stopping and working memory

For purposes of comparison, it is helpful to consider two aspects of executive control that have long been thought to be modular, but have more recently been challenged by a more distributed alternative view.

Influential work by Aron and others highlights the important and seemingly modular role of the right inferior frontal gyrus (rIFG) and anterior insula (aIns) in motor response inhibition, a form of executive control related to stopping (Rubia et al., 2001; Aron et al., 2003; Aron, Robbins, \& Poldrack, 2004; Aron, Robbins, \& Poldrack, 2014). However a recent series of studies challenges this view and proposes an alternative account that is more aligned with a distributed interpretation (Hampshire \& Sharp, 2015; see also Munakata, 2011). Specifically, Hampshire and Sharp propose that stopping is the result of local processing by individual units that engage in lateral inhibition and

694 potentiation, in a manner originally proposed for control of attention in the ventral stream (Desimone \& Duncan, 1995; Chelazzi et al., 1998). In other words, they propose a simple 
695 set of local rules that neuron/agents can follow and produce effective stopping behavior.

696 This view implements classic stopping models and is consistent with relevant unit

697 physiology - that is, with measures of the responses of the putative agents (Band et al., 2003; Boucher et al., 2007; Schall, Stuphorn, \& Brown, 2002). In contrast to Aron and colleagues, they propose that the rIFG/aIns is part of a larger multiple demand cortex that flexibly handles many executive functions, including stopping (Duncan, 2001; Cole \&

702

703

704

705

706

707

708

709 Schneider, 2007; Erika-Florence, Leech, \& Hampshire, 2014). Ultimately, they suggest that stopping may not be a valid psychological construct, but rather a term used to describe intuitively similar behaviors.

Another example comes from the domain of working memory. Classic neurophysiological works by Niki, Fuster and then Goldman-Rakic supported the idea that the DLPFC serves as the site of working memory storage (Kubota \& Niki, 1971; Funahashi, Bruce, \& Goldman-Rakic, 1989; Alexander \& Fuster, 1971; reviewed in Riley \& Constantinidis, 2016). The key evidence for this idea was the fact that single neurons in that region showed systematic changes associated with the contents of working memory. This is a modular view: it proposes that specific rostral regions serve as sites of storage for working memory, while posterior regions implement perception and association. A recent body of work challenges this view and argues for a more distributed alternative (reviewed in Postle, 2006; Pasternak \& Greenlea, 2005; Postle, 2016).

The alternative view proposes that neurons in frontal regions regulate storage (Lebedev et al., 2004; Postle, 2005), but that caudal regions responsible for perception are reactivated during working memory, and that their reactivation serves to store the information on-line (Harrison \& Tong, 2009). This view thus sees perceptual neurons as flexible agents with multiple cognitive roles, including both basic processing and executive control roles. Indeed, further work suggests that modulations in these neurons may alter their responsiveness, thus serving as a form of proactive control that also implements memory-guided decisions (i.e. a matched filter, Machens, Romo, \& Brody, 2005; Miller \& Wang, 2006; David et al., 2008; Jun \& Romo, 2010; Mirabella et al., 2007; Hayden \& Gallant, 2013; Ogawa \& Komatsu, 2004).

Working memory is interesting to use because of its centrality in the history of modular theories (i.e. most theories) of executive control (Baddeley Hitch, 1974; Baddeley, 1996). Especially, the concept of the central executive, which supports the short-term memory in demanding tasks, has been thought to play a diverse control functions. However, subsequent studies discredited the general function of the central executive and rather fractionated its functions to number of the different operations

731

732

733

734

735

736 (Logie, 2016). Thus, as a psychological construct, the concept of the central executive in working memory might no longer be regarded as the modular, centralized function and rather as the functions of the distributed nature.

\section{CONCLUSIONS}

We do not mean to imply that no current work could be classified as distributed. Quite the opposite is true. Many models have distributed aspects (e.g. Botvinick et al., 2001; OReily, Herd, \& Pauli, 2010; Behrman \& Plaut, 2013; Botvinick \& Plaut, 2004; 
741

742

743

744

745

746

747

748

749

750

751

752

753

754

755

756

757

758

759

760

761

762

763

764

765

766

767

768

769

770

771

772

773

774

775

776

777

778

779

780

781

782

783

784

785

786
2010). Instead, our major goals are to highlight the key distinguishing features of distributed and modular systems.

\section{Advantages to a distributed control system}

From the perspective of adaptiveness, there are several advantages of a distributed control system with simple agents (Brooks \& Flynn, 1989). First, because it is selforganized, there is no need to build a special centralized organization system that will link up control elements with their corresponding processors. A modular system requires the equivalent of a telephone switchboard; a distributed one does not. Second, that selforganization gets around the specter of infinite regress (Cooper, 2010). For example, if we have a special centralized organization system, we need another system to build and maintain it, and to monitor its functioning, and so on, ad infinitum. Self-organizing systems are easier developmentally - there is no need to pre-specify their organization genetically or any other way. They are also more robust to damage and can more readily adapt and be amenable to plasticity, such as occurs with learning. They are generally more flexible for novel situations. Finally, and most important, distributed control is a good way to get complex and adaptive behavior from systems consisting of elements that are less complex (Sumpter, 2006). From a theoretical perspective, distributed system makes sense. Many brain functions are distributed, including perception and object recognition, storage of episodic memories, motor planning and execution, and, arguably, economic decision-making (Strait, Sleezer, \& Hayden, 2015; Cisek, 2012; Cisek \& Kalaska, 2010).

\section{How to study distributed executive control systems}

Distributed control systems may be more difficult to study than modular ones with conventional methods. In many studies (including, we hasten to admit, many of our own), we pick out some psychological process of interest. We then ask whether brain activity in some neuron or voxel within a given brain region correlates with a measure of that variable. If we get a positive result, the simplest step is to infer that that variable is reified in the brain. The distributed perspective cautions against this strategy; such correlations may be real, but may only correlate with emergent properties of the system. And if the underlying processes are dissimilar, we will draw false conclusions. In other words, we are always in danger of reifying higher level processes at the lower level.

Instead, the best strategy for dealing with this possibility is a top-down research program. We should come up with specific hypotheses about how distributed control systems might work, and then estimate its expected neural signatures (e.g. Hampshire \& Sharp, 2015). The next step is to identify the results expected from alternative distributed or even modular implementations, and perform the critical test of comparing alternative views. This approach is agnostic about method; it can be applied to unit physiology, neuroimaging, or even reaction times (Louie, Kaw, \& Glimcher, 2013; Chau et al., 2014). And it's worth reiterating that the two modular and the distributed views are not mutually incompatible. In reality, they may exist on a spectrum. And executive control may be heterogeneous; some aspects may be modular while others may be distributed.

The relevant hypotheses will come, as always, from close consideration of the data; especially from attempts to interpret data that conflict with preconceptions. But also, they can come from the animal kingdom, as we have discussed in this review. 
787 Brains are complex distributed systems, and they face many of the same constraints as 788 others. It should not be surprising that they have a great deal in common with ant

789 colonies, bee swarms, and herds of migrating baboons (Couzin, 2009; Sumpter, 206;

790 Passino et al., 2007; Seeley, 2010; Hofstadter, 1980; Hofstadter, 1985, Ch. 25, 26).

791 


\section{REFERENCES}

Afek, Y., Alon, N., Barad, O., Hornstein, E., Barkai, N., \& Bar-Joseph, Z. (2011). A biological solution to a fundamental distributed computing problem. Science 331: 183-185.

Aoki, I. (1982) A simulation study on the schooling mechanism in fish. Bulletin of the Japanese Society of Scientific Fisheries. 48:1081-1088.

Aron, A. R., Fletcher, P. C., Bullmore, E. T., Sahakian, B. J., \& Robbins, T. W. (2003). Stop-signal inhibition disrupted by damage to right inferior frontal gyrus in humans. Nature neuroscience, 6(2), 115-116.

Aron, A. R., Robbins, T. W., \& Poldrack, R. A. (2004). Inhibition and the right inferior frontal cortex. Trends in cognitive sciences, 8(4), 170-177.

Aron, A. R., \& Poldrack, R. A. (2006). Cortical and subcortical contributions to stop signal response inhibition: role of the subthalamic nucleus. The Journal of Neuroscience, 26(9), 2424-2433.

Aron, A.R., Robbins, T.W., \& Poldrack, R.A. (2014). Inhibition and the right inferior frontal cortex: one decade on. Trends Cogn Sci 18:177-185.

Aron, S., Beckers, R., Deneubourg, J. L., \& Pasteels, J. M. (1993). Memory and chemical communication in the orientation of two mass-recruiting ant species. Insectes Sociaux, 40(4), 369-380.

Awh, E., \& Jonides, J. (2001). Overlapping mechanisms of attention and spatial working memory. Trends in Cognitive Sciences. 5:119-126.

Azab, H., \& Hayden, B.Y. (2016). Shared roles of dorsal and subgenual anterior cingulate cortices in economic decisions. BioRixiv. 074484.

Baddeley, A.D., \& Hitch, G. (1974). Working Memory. In: Psychology of Learning and Motivation (Bower GH, ed), pp 47-89. Academic Press. Available at: http://www.sciencedirect.com/science/article/pii/S0079742108604521 [Accessed August 12, 2016].

Baddeley, A. (1996). Exploring the central executive. The Quarterly Journal of Experimental Psychology: Section A, 49(1), 5-28.

Band, G. P., Van Der Molen, M. W., \& Logan, G. D. (2003). Horse-race model simulations of the stop-signal procedure. Acta psychologica, 112(2), 105-142.

Bechara, A. (2005). Decision making, impulse control and loss of willpower to resist drugs: a neurocognitive perspective. Nature neuroscience, 8(11), 1458-1463.

Beckers, R., Deneubourg, J. L., \& Goss, S. (1992). Trails and U-turns in the selection of a path by the ant Lasius niger. Journal of theoretical biology, 159(4), 397-415.

Beekman, M., Sumpter, D. J., \& Ratnieks, F. L. (2001). Phase transition between disordered and ordered foraging in Pharaoh's ants. Proceedings of the National Academy of Sciences, 98(17), 9703-9706. 
Behrens, T. E., Woolrich, M. W., Walton, M. E., \& Rushworth, M. F. (2007). Learning the value of information in an uncertain world. Nature neuroscience, 10(9), 12141221.

Behrmann, M., \& Plaut, D. C. (2013). Distributed circuits, not circumscribed centers, mediate visual recognition. Trends in cognitive sciences, 17(5), 210-219.

Bergman, G., \& Donner, K. O. (1964). An analysis of the spring migration of the common scoter and the long-tailed duck in southern Finland. Acta Zool Fenn. 105:1-59.

Bertolero, M.A., Yeo, B.T.T., \& D’Esposito, M. (2015). The modular and integrative functional architecture of the human brain. Proc Natl Acad Sci 112:E6798E6807.

Biro, D., Sumpter, D. J., Meade, J., \& Guilford, T. (2006). From compromise to leadership in pigeon homing. Current Biology, 16(21), 2123-2128.

Blanchard, T.C., Hayden, B.Y., \& Bromberg-Martin, E.S. (2015). Orbitofrontal Cortex Uses Distinct Codes for Different Choice Attributes in Decisions Motivated by Curiosity. Neuron 85:602-614.

Blanchard, T. C., Strait, C. E., \& Hayden, B. Y. (2015). Ramping ensemble activity in dorsal anterior cingulate neurons during persistent commitment to a decision. Journal of neurophysiology, 114(4), 2439-2449.

Bogacz, R., Wagenmakers, E. J., Forstmann, B. U., \& Nieuwenhuis, S. (2010). The neural basis of the speed-accuracy tradeoff. Trends in neurosciences, 33(1), 1016.

Bonabeau, E., Dorigo, M., \& Theraulaz, G. (1999). Swarm intelligence: from natural to artificial systems (No. 1). Oxford university press.

Botvinick, M., Nystrom, L. E., Fissell, K., Carter, C. S., \& Cohen, J. D. (1999). Conflict monitoring versus selection-for-action in anterior cingulate cortex. Nature, 402(6758), 179-181.

Botvinick, M.M., Braver, T.S., Barch, D.M., Carter, C.S., \& Cohen, J.D. (2001). Conflict monitoring and cognitive control. Psychol Rev 108:624-652.

Botvinick, M. M., Braver, T. S., Barch, D. M., Carter, C. S., \& Cohen, J. D. (2001). Evaluating the demand for control: Anterior cingulate cortex and conflict monitoring. Psychological Review, 108(3), 624-652.

Botvinick, M. M., Cohen, J. D., \& Carter, C. S. (2004). Conflict monitoring and anterior cingulate cortex: an update. Trends in cognitive sciences, 8(12), 539-546.

Botvinick, M. M., \& Cohen, J. D. (2014). The computational and neural basis of cognitive control: charted territory and new frontiers. Cognitive science, $38(6)$, 1249-1285.

Botvinick, M., \& Plaut, D. C. (2004). Doing without schema hierarchies: a recurrent connectionist approach to normal and impaired routine sequential action. Psychological review, 111(2), 395. 
Botvinick, M. M., \& Plaut, D. C. (2006). Short-term memory for serial order: a recurrent neural network model. Psychological review, 113(2), 201.

Boucher, L., Palmeri, T. J., Logan, G. D., \& Schall, J. D. (2007). Inhibitory control in mind and brain: an interactive race model of countermanding saccades. Psychological review, 114(2), 376.

Braver, T.S., \& Barch, D.M. (2006). Extracting core components of cognitive control. Trends Cogn Sci 10:529-532.

Bressler, S.L., \& Menon, V. (2010). Large-scale brain networks in cognition: emerging methods and principles. Trends in Cognitive Sciences 14:277-290.

Brooks, R. A., \& Flynn, A. M. (1989). Fast, cheap and out of control (No. AI-M-1182). Massachusetts Inst of Tech Cambridge Artificial Intelligence Lab.

Buckley, M. J., Mansouri, F. A., Hoda, H., Mahboubi, M., Browning, P. G., Kwok, S. C., ... \& Tanaka, K. (2009). Dissociable components of rule-guided behavior depend on distinct medial and prefrontal regions. Science, 325(5936), 52-58.

Busemeyer, J. R., \& Townsend, J. T. (1993). Decision field theory: a dynamic-cognitive approach to decision making in an uncertain environment. Psychological review, $100(3), 432$.

Bush, G., Luu, P., \& Posner, M. I. (2000). Cognitive and emotional influences in anterior cingulate cortex. Trends in cognitive sciences, 4(6), 215-222.

Cai, X., \& Padoa-Schioppa, C. (2012). Neuronal encoding of subjective value in dorsal and ventral anterior cingulate cortex. The Journal of Neuroscience, 32(11), 37913808 .

Camazine, S., Visscher, P. K., Finley, J., \& Vetter, R. S. (1999). House-hunting by honey bee swarms: collective decisions and individual behaviors. Insectes Sociaux, 46(4), 348-360.

Cisek, P., \& Kalaska, J. F. (2010). Neural mechanisms for interacting with a world full of action choices. Annual review of neuroscience, 33, 269-298.

Cisek, P. (2012). Making decisions through a distributed consensus. Current opinion in neurobiology, 22(6), 927-936.

Chafee, M.V., \& Goldman-Rakic, P.S. (1998). Matching Patterns of Activity in Primate Prefrontal Area 8a and Parietal Area 7ip Neurons During a Spatial Working MemoryTask. J Neurophysiol 79:2919-2940.

Chau, B. K., Kolling, N., Hunt, L. T., Walton, M. E., \& Rushworth, M. F. (2014). A neural mechanism underlying failure of optimal choice with multiple alternatives. Nature neuroscience, 17(3), 463-470.

Chelazzi, L., Duncan, J., Miller, E. K., \& Desimone, R. (1998). Responses of neurons in inferior temporal cortex during memory-guided visual search. Journal of neurophysiology, 80(6), 2918-2940.

Chittka, L., Dyer, A. G., Bock, F., \& Dornhaus, A. (2003). Psychophysics: bees trade off foraging speed for accuracy. Nature, 424(6947), 388-388. 
Chittka, L. (2004). Dances as windows into insect perception. PLoS Biol, 2(7), e216.

Chittka, L., Skorupski, P., \& Raine, N. E. (2009). Speed-accuracy tradeoffs in animal decision making. Trends in Ecology \& Evolution, 24(7), 400-407.

Chudasama, Y., Daniels, T.E., Gorrin, D.P., Rhodes, S.E.V., Rudebeck, P.H., \& Murray, E.A. (2013). The role of the anterior cingulate cortex in choices based on reward value and reward contingency. Cerebral Cortex. 23:2884-2899.

Codling, E. A., Pitchford, J. W., \& Simpson, S. D. (2007). Group navigation and the "many-wrongs principle" in models of animal movement. Ecology, 88(7), 18641870.

Cole, M.W., \& Schneider, W. (2007). The cognitive control network: Integrated cortical regions with dissociable functions. NeuroImage 37:343-360.

Conradt, L., \& Roper, T. J. (2003). Group decision-making in animals. Nature, 421(6919), 155-158.

Cooper, R. P. (2010). Cognitive control: componential or emergent?. Topics in Cognitive Science, 2(4), 598-613.

Couzin, I. D., \& Krause, J. (2003). Self-organization and collective behavior in vertebrates. Advances in the Study of Behavior, 32, 1-75.

Couzin, I. D. (2009). Collective cognition in animal groups. Trends in cognitive sciences, 13(1), 36-43.

Couzin, I. D., Krause, J., James, R., Ruxton, G. D., \& Franks, N. R. (2002). Collective memory and spatial sorting in animal groups. Journal of theoretical biology, 218(1), 1-11.

Couzin, I. D., Krause, J., Franks, N. R., \& Levin, S. A. (2005). Effective leadership and decision-making in animal groups on the move. Nature, 433(7025), 513-516.

Craddock, R.C., Tungaraza, R.L., \& Milham, M.P. (2015). Connectomics and new approaches for analyzing human brain functional connectivity. 4:13-25.

David, S. V., Hayden, B. Y., Mazer, J. A., \& Gallant, J. L. (2008). Attention to stimulus features shifts spectral tuning of V4 neurons during natural vision. Neuron, 59(3), 509-521.

Daw, N.D., O’Doherty, J.P., Dayan, P., Seymour, B., \& Dolan, R.J. (2006). Cortical substrates for exploratory decisions in humans. Nature 441:876-879.

Delsuc, F. (2003). Army ants trapped by their evolutionary history. PLoS Biol, 1(2), e37.

Desimone, R., \& Duncan, J. (1995). Neural mechanisms of selective visual attention. Annual review of neuroscience, 18(1), 193-222.

Duncan, J. (2001). An adaptive coding model of neural function in prefrontal cortex. Nature Reviews Neuroscience, 2(11), 820-829.

Duncan, J., Emslie, H., Williams, P., Johnson, R., \& Freer, C. (1996). Intelligence and the frontal lobe: The organization of goal-directed behavior. Cognitive psychology, 30(3), 257-303. 
Dussutour, A., Latty, T., Beekman, M., \& Simpson, S. J. (2010). Amoeboid organism solves complex nutritional challenges. Proceedings of the National Academy of Sciences, 107(10), 4607-4611.

Dyer, J. R., Ioannou, C. C., Morrell, L. J., Croft, D. P., Couzin, I. D., Waters, D. A., \& Krause, J. (2008). Consensus decision making in human crowds. Animal Behaviour, 75(2), 461-470.

Ebitz, R.B., \& Platt, M.L. (2015). Neuronal Activity in primate dorsal anterior cingulate cortex signals task conflict and predicts adjustments in pupil-linked arousal. Neuron. 85: 628-640.

Ebitz, R.B., \& Hayden, B.Y. (2016). Dorsal anterior cingulate: a rorshach test for cognitive neuroscience. Nature Neuroscience. 19:1-3.

Erika-Florence, M., Leech, R., \& Hampshire, A. (2014). A functional network perspective on response inhibition and attentional control. Nature communications, 5.

Farah, M. J. (1994). Neuropsychological inference with an interactive brain: A critique of the "locality" assumption. Behavioral and Brain Sciences, 17(01), 43-61.

Fischhoff, I. R., Sundaresan, S. R., Cordingley, J., Larkin, H. M., Sellier, M. J., \& Rubenstein, D. I. (2007). Social relationships and reproductive state influence leadership roles in movements of plains zebra, Equus burchellii. Animal Behaviour, 73(5), 825-831.

Floresco, S. B. (2015). The nucleus accumbens: an interface between cognition, emotion, and action. Annual review of psychology, 66, 25-52.

Fodor, J.A. (1983). The Modularity of Mind: An Essay on Faculty Psychology. MIT Press.

Frank, M. J., Scheres, A., \& Sherman, S. J. (2007). Understanding decision-making deficits in neurological conditions: insights from models of natural action selection. Philosophical Transactions of the Royal Society of London B: Biological Sciences, 362(1485), 1641-1654.

Franks, N. R., Pratt, S. C., Mallon, E. B., Britton, N. F., \& Sumpter, D. J. (2002). Information flow, opinion polling and collective intelligence in house-hunting social insects. Philosophical Transactions of the Royal Society of London B: Biological Sciences, 357(1427), 1567-1583.

Franks, N. R., Dornhaus, A., Fitzsimmons, J. P., \& Stevens, M. (2003). Speed versus accuracy in collective decision making. Proceedings of the Royal Society of London B: Biological Sciences, 270(1532), 2457-2463.

Forstmann, B. U., Dutilh, G., Brown, S., Neumann, J., Von Cramon, D. Y., Ridderinkhof, K. R., \& Wagenmakers, E. J. (2008). Striatum and pre-SMA facilitate decisionmaking under time pressure. Proceedings of the National Academy of Sciences, 105(45), 17538-17542. 
Funahashi, S., Bruce, C. J., \& Goldman-Rakic, P. S. (1989). Mnemonic coding of visual space in the monkey's dorsolateral prefrontal cortex. Journal of neurophysiology, 61(2), 331-349.

Fuster, J. M., \& Alexander, G. E. (1971). Neuron activity related to short-term memory. Science, 173(3997), 652-654.

Gallistel, C. R. (2013). The organization of action: A new synthesis. Psychology Press.

Gigerenzer, G., \& Goldstein, D. G. (1996). Reasoning the fast and frugal way: models of bounded rationality. Psychological review, 103(4), 650.

Giraldeau, L. A., Valone, T. J., \& Templeton, J. J. (2002). Potential disadvantages of using socially acquired information. Philosophical Transactions of the Royal Society of London B: Biological Sciences, 357(1427), 1559-1566.

Grossberg, S. (1974). Classical and instrumental learning by neural networks. Prog Theor Biol 3:42-47.

Grünbaum, D. (1998). Schooling as a strategy for taxis in a noisy environment. Evolutionary Ecology, 12(5), 503-522.

Hamilton, W.J. (1967). Social aspects of bir orientation mechanisms. In Animal Orientation and Navigation. Storm, RM ed., 57-71, Oregon State University Press.

Hampshire, A., \& Sharp, D. J. (2015). Contrasting network and modular perspectives on inhibitory control. Trends in cognitive sciences, 19(8), 445-452.

Hare, T.A., Camerer, C.F., Rangel, A. (2009). Self-Control in Decision-Making Involves Modulation of the vmPFC Valuation System. Science 324:646-648.

Hare, T.A., Schultz, W., Camere, C.F., O'Doherty, J.P., \& Rangel, A. (2011).

Transformation of stimulus value signals into motor commands during simple choice. Proc. Natl. Acad. Sci. 108:18120-18125.

Harrison, S. A., \& Tong, F. (2009). Decoding reveals the contents of visual working memory in early visual areas. Nature, 458(7238), 632-635.

Hayden, B.Y., Nair, A.C., McCoy, A.N., Platt, M.L. (2008). Posterior cingulate cortex mediates outcome-contingent allocation of behavior. Neuron. 60:19-25.

Hayden, B. Y., Pearson, J. M., \& Platt, M. L. (2009). Fictive reward signals in the anterior cingulate cortex. science, 324(5929), 948-950.

Hayden, B. Y., \& Platt, M. L. (2010). Neurons in anterior cingulate cortex multiplex information about reward and action. The Journal of Neuroscience, 30(9), 33393346.

Hayden, B., Smith, D. V., \& Platt, M. (2010). Cognitive control signals in posterior cingulate cortex. Frontiers in human neuroscience, 4, 223.

Hayden, B. Y., Heilbronner, S. R., Pearson, J. M., \& Platt, M. L. (2011). Surprise signals in anterior cingulate cortex: neuronal encoding of unsigned reward prediction errors driving adjustment in behavior. The Journal of Neuroscience, 31(11), 41784187. 
Hayden, B. Y., Pearson, J. M., \& Platt, M. L. (2011). Neuronal basis of sequential foraging decisions in a patchy environment. Nature neuroscience, 14(7), 933-939.

Hayden, B.Y., Heilbronner, S.R. (2014). All that glitters is not reward signal. Nature Neuroscience. 17:1142-1144.

Hayden, B.Y., \& Gallant, J. (2013). Working memory and decision processes in visual area v4. Frontiers in neuroscience, $7,18$.

Heilbronner, S., Hayden, B. Y., \& Platt, M. (2011). Decision salience signals in posterior cingulate cortex. Frontiers in neuroscience, 5, 55.

Heilbronner, S. R., \& Haber, S. N. (2014). Frontal cortical and subcortical projections provide a basis for segmenting the cingulum bundle: implications for neuroimaging and psychiatric disorders. The Journal of Neuroscience, 34(30), 10041-10054.

Heilbronner, S.R., \& Platt, M.L. (2013). Causal evidence of performance monitoring by neurons in posterior cingulate cortex during learning. Neuron. 80:1384-1391.

Heilbronner, S. R., \& Hayden, B. Y. (2016). Dorsal Anterior Cingulate Cortex: A Bottom-Up View. Annual review of neuroscience.

Heilbronner, S. R., Rodriguez-Romaguera, J., Quirk, G. J., Groenewegen, H. J., \& Haber, S. N. (2016). Circuit Based Cortico-Striatal Homologies between Rat and Primate. Biological Psychiatry.

Helbing, D., Keltsch, J., \& Molnar, P. (1997). Modelling the evolution of human trail systems. Nature, 388(6637), 47-50.

Hernández, A., Nácher, V., Luna, R., Zainos, A., Lemus, L., Alvarez, M., Vázquez, Y., Camarillo, L., \& Romo, R. (2010). Decoding a Perceptual Decision Process across Cortex. Neuron 66:300-314.

Hillman, K.L., Bilkey, D.K. (2010). Neurons in the rat anterior cingulate cortex dynamically encode cost-benefit in a spatial decision-making task. Journal of Neuroscience. 30:7705-7713.

Hillman, K.L., Bilkey, D.K. (2012). Neural encoding of competitive effort in the anterior cingulate cortex. Nature Neuroscience. 9:1290-1298.

Hinton, G. E., \& Salakhutdinov, R. R. (2006). Reducing the dimensionality of data with neural networks. Science, 313(5786), 504-507.

Hofstadter, D. R. (1980). Godel, Escher, Bach. New Society.

Hofstadter, DR. (1985). Who shoves whom around inside the careenium? or, what is the meaning of the word "I". In Hofstadter, D.R. Metamagical themas: Questing for the essence of mind and pattern. (chapter 25). Basic books.

Hofstadter, DR. (1985). Waking up from the boolean dream, or subcognition as computation. In Hofstadter, D.R. Metamagical themas: Questing for the essence of mind and pattern. (chapter 26). Basic books. 
Hosokawa, T., Kennerley, S. W., Sloan, J., \& Wallis, J. D. (2013). Single-neuron mechanisms underlying cost-benefit analysis in frontal cortex. The Journal of Neuroscience, 33(44), 17385-17397.

Hölldobler, B., \& Wilson, E. O. (1990). The ants. Harvard University Press.

Holroyd, C. B., \& Coles, M. G. (2002). The neural basis of human error processing: reinforcement learning, dopamine, and the error-related negativity. Psychological review, 109(4), 679.

Hopfield, J.J. (1982). Neural networks and physical systems with emergent collective computational abilities. Proc Natl Acad Sci 79:2554-2558.

Houston, A. I., Kacelnik, A., \& McNamara, J. O. H. N. (1982). Some learning rules for acquiring information. Functional ontogeny, 1, 140-191.

Ito, S., Stuphorn, V., Brown, J. W., \& Schall, J. D. (2003). Performance monitoring by the anterior cingulate cortex during saccade countermanding. Science, 302(5642), $120-122$.

Ivanoff, J., Branning, P., \& Marois, R. (2008). fMRI evidence for a dual process account of the speed-accuracy tradeoff in decision-making. PLoS one, 3(7), e2635.

Isomura, Y., Ito, Y., Akazawa, T., Nambu, A., \& Takada, M. (2003). Neural coding of "attention for action" and "response selection" in primate anterior cingulate cortex. The Journal of neuroscience, 23(22), 8002-8012.

Jackson, D. E., \& Châline, N. (2007). Modulation of pheromone trail strength with food quality in Pharaoh's ant, Monomorium pharaonis. Animal behaviour, 74(3), 463 470.

Jin, X., \& Costa, R. M. (2010). Start/stop signals emerge in nigrostriatal circuits during sequence learning. Nature, 466(7305), 457-462.

Jun, J. K., Miller, P., Hernández, A., Zainos, A., Lemus, L., Brody, C. D., \& Romo, R. (2010). Heterogenous population coding of a short-term memory and decision task. The Journal of Neuroscience, 30(3), 916-929.

Kacelnik, A., Vasconcelos, M., Monteiro, T., \& Aw, J. (2011). Darwin's “tug-of-war" vs. starlings' "horse-racing": how adaptations for sequential encounters drive simultaneous choice. Behavioral Ecology and Sociobiology, 65(3), 547-558.

Kalivas, P.W., Volkow, N.D. (2005). The neural basis of addiction: a pathology of motivation and choice. American Journal of Psychiatry. 162:1403-1413.

Kanwisher, N., McDermott, J., \& Chun, M.M. (1997). The Fusiform Face Area: A Module in Human Extrastriate Cortex Specialized for Face Perception. J Neurosci $17: 4302-4311$.

Kaplan, H. B., \& Greenberg, E. P. (1985). Diffusion of autoinducer is involved in regulation of the Vibrio fischeri luminescence system. Journal of bacteriology, 163(3), 1210-1214. 
Kennerley, S. W., Walton, M. E., Behrens, T. E., Buckley, M. J., \& Rushworth, M. F. (2006). Optimal decision making and the anterior cingulate cortex. Nature neuroscience, 9(7), 940-947.

Kennerley, S. W., Dahmubed, A. F., Lara, A. H., \& Wallis, J. D. (2009). Neurons in the frontal lobe encode the value of multiple decision variables. Journal of cognitive neuroscience, 21(6), 1162-1178.

Kidd, C., \& Hayden, B.Y. (2015). The psychology and neuroscience of curiosity. Neuron $88: 449-460$.

Kim, J.N., \& Shadlen, M.N. (1999). Neural correlates of a decision in the dorsolateral prefrontal cortex of the macaque. Nat Neurosci 2:176-185.

Kolling, N., Behrens, T.E.J., Mars, R.B., \& Rushworth, M.F.S. (2012) Neural mechanisms of foraging. Science. 336:95-98.

Kolling, N., Behrens, T. E. J., Wittmann, M. K., \& Rushworth, M. F. S. (2016). Multiple signals in anterior cingulate cortex. Current opinion in neurobiology, 37, 36-43.

Knoch, D., \& Fehr, E. (2007). Resisting the Power of Temptations. Ann N Y Acad Sci 1104:123-134.

Kristan, W.B., \& Shaw, BK. (1997). Population coding and behavioral choice. Current Opinion in Neurobiology. 7:826-831.

Kubota, K., \& Niki, H. (1971). Prefrontal cortical unit activity and delayed alternation performance in monkeys. Journal of Neurophysiology.

Lashley, K. (1951). The problem of serial order in behavior. In: Cerebral mechanisms in behavior; the Hixon Symposium, pp 112-146. Oxford, England: Wiley.

LeCun, Y., Bengio, Y., \& Hinton, G. (2015). Deep learning. Nature, 521(7553), 436-444.

Lebedev, M. A., Messinger, A., Kralik, J. D., \& Wise, S. P. (2004). Representation of attended versus remembered locations in prefrontal cortex. PLoS Biol, 2(11), e365.

Lenartowicz, A., Kalar, D. J., Congdon, E., \& Poldrack, R. A. (2010). Towards an ontology of cognitive control. Topics in Cognitive Science, 2(4), 678-692.

Levine, B., Stuss, D. T., Milberg, W. P., Alexander, M. P., Schwartz, M., \& MacDonald, R. (1998). The effects of focal and diffuse brain damage on strategy application: Evidence from focal lesions, traumatic brain injury and normal aging. Journal of the International Neuropsychological Society, 4(03), 247-264.

Lindauer, M. (1957). Communication among the honeybees and stingless bees of India. Bee World, 38(1), 3-14.

Logie, R. H. (2016). Retiring the central executive. The Quarterly Journal of Experimental Psychology, 1-17.

Louie, K., Khaw, M. W., \& Glimcher, P. W. (2013). Normalization is a general neural mechanism for context-dependent decision making. Proceedings of the National Academy of Sciences, 110(15), 6139-6144. 
Luk, C. H., \& Wallis, J. D. (2009). Dynamic encoding of responses and outcomes by neurons in medial prefrontal cortex. The Journal of Neuroscience, 29(23), 75267539.

Ma, L., Hyman, J. M., Phillips, A. G., \& Seamans, J. K. (2014). Tracking progress toward a goal in corticostriatal ensembles. The Journal of Neuroscience, 34(6), 2244-2253.

Machens, C. K., Romo, R., \& Brody, C. D. (2005). Flexible control of mutual inhibition: a neural model of two-interval discrimination. Science, 307(5712), 1121-1124.

Mallon, E., Pratt, S., \& Franks, N. (2001). Individual and collective decision-making during nest site selection by the ant Leptothorax albipennis. Behavioral Ecology and Sociobiology, 50(4), 352-359.

Mansouri, F. A., Buckley, M. J., \& Tanaka, K. (2007). Mnemonic function of the dorsolateral prefrontal cortex in conflict-induced behavioral adjustment. Science, 318(5852), 987-990.

Matsumoto, M., Matsumoto, K., Abe, H., \& Tanaka, K. (2007). Medial prefrontal cell activity signaling prediction errors of action values. Nature Neuroscience. 10:647658.

McFall-Ngai, M. (2014). Divining the essence of symbiosis: insights from the squidvibrio model. PLoS Biol, 12(2), e1001783.

Milad, M.R., Rauch, S.L. (2012). Obsessive-compulsive disorder: beyond segregated cortico-striatal pathways. Trends in cognitive science. 16:43-52.

Miller, P., \& Wang, X. J. (2006). Inhibitory control by an integral feedback signal in prefrontal cortex: a model of discrimination between sequential stimuli.

Proceedings of the National Academy of Sciences of the United States of America, 103(1), 201-206.

Mirabella, G., Bertini, G., Samengo, I., Kilavik, B. E., Frilli, D., Della Libera, C., \& Chelazzi, L. (2007). Neurons in area V4 of the macaque translate attended visual features into behaviorally relevant categories. Neuron, 54(2), 303-318.

McClelland, J. L., Rumelhart, D. E., \& PDP Research Group. (1987). Parallel distributed processing (Vol. 2). Cambridge, MA: MIT press.

McClelland, J.L., Botvinick, M.M., Noelle, D.C., Plaut, D.C., Rogers, T.T., Seidenberg, M.S., \& Smith, L.B. (2010). Letting structure emerge: connectionist and dynamical systems approaches to cognition. Trends Cogn Sci 14:348-356.

Miller, E.K. (2000). The prefontral cortex and cognitive control. Nat Rev Neurosci 1:5965.

Miller, E.K., \& Cohen, J.D. (2001). An Integrative Theory of Prefrontal Cortex Function. Annu Rev Neurosci 24:167-202.

Miller, M. B., \& Bassler, B. L. (2001). Quorum sensing in bacteria. Annual Reviews in Microbiology, 55(1), 165-199. 
Misic, B., \& Sporns, O. (2016). From regions to connections and networks: new bridges between brain and behavior. Current Opinion in Neurobiology 40:1-7

Minsky, M. (1988). Society of mind. Simon and Schuster.

Mitchell, M. (2009). Complexity: A guided tour. Oxford University Press.

Morecraft, R.J., \& Van Hoesen, G.W. (1997). Convergence of limbic input to the cingulate motor cortex in the rhesus monkey. Brain Research Bulletin. 45:209232.

Munakata, Y., Herd, S. A., Chatham, C. H., Depue, B. E., Banich, M. T., \& O'Reilly, R. C. (2011). A unified framework for inhibitory control. Trends in cognitive sciences, 15(10), 453-459.

Nakamura, K., Roesch, M. R., \& Olson, C. R. (2005). Neuronal activity in macaque SEF and ACC during performance of tasks involving conflict. Journal of neurophysiology, 93(2), 884-908.

Navlakha, S., \& Bar-Joseph, Z. (2011). Algorithms in nature: the convergence of systems biology and computational thinking. Molecular Systems Biology7: 546-557.

Néda, Z., Ravasz, E., Brechet, Y., Vicsek, T., \& Barabási, A. L. (2000). Self-organizing processes: The sound of many hands clapping. Nature, 403(6772), 849-850.

Nealson, K. H., \& Hastings, J. W. (1979). Bacterial bioluminescence: its control and ecological significance. Microbiological reviews, 43(4), 496.

Niv, Y., Daw, N. D., Joel, D., \& Dayan, P. (2007). Tonic dopamine: opportunity costs and the control of response vigor. Psychopharmacology, 191(3), 507-520.

Norman, D.A., \& Shallice, T. (1986). Attention to Action. In: Consciousness and SelfRegulation (Davidson RJ, Schwartz GE, Shapiro D, eds), pp 1-18. Springer US. Available at: http://link.springer.com/chapter/10.1007/978-1-4757-0629-1_1 [Accessed August 12, 2016].

Norsworthy, A. N., \& Visick, K. L. (2014). Gimme shelter: howVibrio fischeri successfully navigates an animal's multiple environments. Vibrio ecology, pathogenesis and evolution, 142.

Ogawa, T., \& Komatsu, H. (2004). Target selection in area V4 during a multidimensional visual search task. The Journal of Neuroscience, 24(28), 6371-6382.

O'Reilly, R. C., Herd, S. A., \& Pauli, W. M. (2010). Computational models of cognitive control. Current opinion in neurobiology, 20(2), 257-261.

Pais, D., Hogan, P.M., Schlegel, T., Franks, N.R., Leonard, N.E., \& Marshall, J.A.R. (2013). A mechanism for value-sensitive decision-making. PloS One. 8:e73216

Passino, K.M., Seeley, T.D., \& Visscher, P.K. (2007). Swarm cognition in honey bees. Behav Ecol Sociobiol 62:401-414.

Passingham, R. E., Stephan, K. E., \& Kötter, R. (2002). The anatomical basis of functional localization in the cortex. Nature Reviews Neuroscience, 3(8), 606-616. 
Pasternak, T., \& Greenlee, M. W. (2005). Working memory in primate sensory systems. Nature Reviews Neuroscience, 6(2), 97-107.

Parvizi, J., Rangarajan, V., Shier, W.R., Desai, N., \& Greicius, M.D. (2013). The will to persevere induced by electrical stimulation of the human cingulate gyrus. Neuron. 80:1359-1367.

Paus, T. S. (2001). Primate anterior cingulate cortex: where motor control, drive and cognition interface. Nature Reviews Neuroscience, 2(6), 417-424.

Pearson, J. P., Van Delden, C., \& Iglewski, B. H. (1999). Active efflux and diffusion are involved in transport of Pseudomonas aeruginosa cell-to-cell signals. Journal of bacteriology, 181(4), 1203-1210.

Pearson, J.M., Heilbronner, S.R., Barack, D.L., Hayden, B.Y., \& Platt, M.L. (2011). Posterior cingulate cortex: adapting behavior to a changing world. Trends Cogn Sci 15:143-151.

Pezzulo, G., Cisek, P. (2016). Navigating the Affordance Landscape: Feedback Control as a Process Model of Behavior and Cognition. Trends Cogn Sci 20:414-424.

Picton, T. W., Stuss, D. T., Alexander, M. P., Shallice, T., Binns, M. A., \& Gillingham, S. (2007). Effects of focal frontal lesions on response inhibition. Cerebral Cortex, 17(4), 826-838.

Plaut, D.C. (1995). Double Dissociation without modularity: Evidence from connectionist neuropsychology. Journal of Clinical and Experimental Neuropsychology. 17:291-321.

Posner, M.I., Snyder, \& C.R.R. (1975). Facilitation and inhibition in the processing of signals. Atten Perform V:669-682.

Postle, B. R. (2005). Delay-period activity in the prefrontal cortex: one function is sensory gating. Journal of cognitive neuroscience, 17(11), 1679-1690.

Postle, B. R. (2006). Working memory as an emergent property of the mind and brain. Neuroscience, 139(1), 23-38.

Postle, B. R. (2016). How Does the Brain Keep Information "in Mind"?. Current Directions in Psychological Science, 25(3), 151-156.

Porter, D. P., \& Smith, V. L. (1994). Stock market bubbles in the laboratory. Applied Mathematical Finance, 1(2), 111-128.

Pratt, S. C., Mallon, E. B., Sumpter, D. J., \& Franks, N. R. (2002). Quorum sensing, recruitment, and collective decision-making during colony emigration by the ant Leptothorax albipennis. Behavioral Ecology and Sociobiology, 52(2), 117-127.

Procyk, E., Tanaka, Y. L., \& Joseph, J. P. (2000). Anterior cingulate activity during routine and non-routine sequential behaviors in macaques. Nature neuroscience, $3(5), 502-508$.

Reebs, S. G. (2000). Can a minority of informed leaders determine the foraging movements of a fish shoal?. Animal behaviour, 59(2), 403-409. 
Reynolds, C. W. (1987). Flocks, herds and schools: A distributed behavioral model. ACM SIGGRAPH computer graphics, 21(4), 25-34.

Ridderinkhof, K.R., van den Wildenberg, W.P.M., Segalowitz, S.J., \& Carter, C.S. (2004). Neurocognitive mechanisms of cognitive control: The role of prefrontal cortex in action selection, response inhibition, performance monitoring, and reward-based learning. Brain Cogn 56:129-140.

Riley, M. R., \& Constantinidis, C. (2015). Role of prefrontal persistent activity in working memory. Frontiers in systems neuroscience, 9.

Roitman, J. D., \& Shadlen, M. N. (2002). Response of neurons in the lateral intraparietal area during a combined visual discrimination reaction time task. The Journal of neuroscience, 22(21), 9475-9489.

Robson, S. K., \& Traniello, J. F. (1999). Key individuals and the organisation of labor in ants. In Information processing in social insects (pp. 239-259). Birkhäuser Basel.

Rougier, N.P., Noelle, D.C., Braver, T.S., Cohen, J.D., \& O'Reilly, R.C. (2005). Prefontal cortex and flexible cognitive control: Rules without symbols. PNAS. 102:73387343.

Rubia, K., Russell, T., Overmeyer, S., Brammer, M. J., Bullmore, E. T., Sharma, T., ... \& Taylor, E. (2001). Mapping motor inhibition: conjunctive brain activations across different versions of go/no-go and stop tasks. Neuroimage, 13(2), 250-261.

Rudebeck, P. H., Walton, M. E., Smyth, A. N., Bannerman, D. M., \& Rushworth, M. F. (2006). Separate neural pathways process different decision costs. Nature neuroscience, 9(9), 1161-1168.

Rumelhart, D.E., McClelland, J.L., Group, P.R., \& others (1988) Parallel distributed processing. IEEE. Available at: http://www.cs.toronto.edu/ fritz/absps/pdp2.pdf [Accessed August 12, 2016].

Rushworth, M. F., Noonan, M. P., Boorman, E. D., Walton, M. E., \& Behrens, T. E. (2011). Frontal cortex and reward-guided learning and decision-making. Neuron, 70(6), 1054-1069.

Ryle, G. (1949). Meaning and necessity. philosophy, 24(88), 69-76.

Schall, J. D. (2001). Neural basis of deciding, choosing and acting. Nature Reviews Neuroscience, 2(1), 33-42.

Schall, J. D., Stuphorn, V., \& Brown, J. W. (2002). Monitoring and control of action by the frontal lobes. Neuron, 36(2), 309-322.

Schoenbaum, G., Roesch, M.R., Stalnaker, T.A., Takahasi, Y.K. (2009). A new perspective on the role of the orbitofrontal cortex in adaptive behavior. Nature Reveiws Neuroscience. 10:885-863.

Seeley, T. D. (2010). Honeybee democracy. Princeton University Press.

Seeley, T. D., \& Buhrman, S. C. (1999). Group decision making in swarms of honey bees. Behavioral Ecology and Sociobiology, 45(1), 19-31. 
Seo, H., \& Lee, D. (2007). Temporal filtering of reward signals in the dorsal anterior cingulate cortex during a mixed-strategy game. The Journal of Neuroscience, 27(31), 8366-8377.

Shallice, T. (1982). Specific impairments of planning. Philosophical Transactions of the Royal Society of London B: Biological Sciences, 298(1089), 199-209.

Sheth, S.A., Mian, M.K., Patel, S.R., Asaad, W.F., Williams, Z.M., Dougherty, D.D., Bush, G., \& Eskandar, E.N. (2012). Human dorsal anterior cingulate cortex neurons mediate ongoing behavioural adaptation. Nature. 488:218-222

Shenhav, A., Botvinick, M.M., \& Cohen, J.D. (2013). The Expected Value of Control: An Integrative Theory of Anterior Cingulate Cortex Function. Neuron 79:217240.

Shenhav, A., Straccia, M. A., Botvinick, M. M., \& Cohen, J. D. (2016). Dorsal anterior cingulate and ventromedial prefrontal cortex have inverse roles in both foraging and economic choice. bioRxiv, 046276.

Shidara, M., \& Richmond, B. J. (2002). Anterior cingulate: single neuronal signals related to degree of reward expectancy. Science, 296(5573), 1709-1711.

Shiffrin, R.M., \& Schneider, W. (1977). Controlled and automatic human information processing: II. Perceptual learning, automatic attending and a general theory. Psychol Rev 84:127-190.

Shima, K., \& Tanji, J. (1998). Role for cingulate motor area cells in voluntary movement selection based on reward. Science, 282(5392), 1335-1338.

Simons, A. M. (2004). Many wrongs: the advantage of group navigation. Trends in ecology \& evolution, 19(9), 453-455.

Sleezer, B.J., \& Hayden, B.Y. (2016). Differential Contributions of Ventral and Dorsal Striatum to Early and Late Phases of Cognitive Set Reconfiguration. J Cogn Neurosci:1-16.

Sleezer, B.J., Cstagno, M.D., \& Hayden, B.Y. (in Press). Rule encoding in orbitalfrontal cortex and striatum guides selection. Journal of Neuroscience.

Smith, V. L., Suchanek, G. L., \& Williams, A. W. (1988). Bubbles, crashes, and endogenous expectations in experimental spot asset markets. Econometrica: Journal of the Econometric Society, 1119-1151.

Sporns, O., Tononi, G., \& Kotter, R. (2005). The human connectome: a structural description of the human brain. PLoS Computational Biology 1:245-51.

Sporns, O., \& Betzel, R.F. (2016). Modular Brain Networks. Annual Review of Psychology 67:613:640.

Stevens, A. M., Dolan, K. M., \& Greenberg, E. P. (1994). Synergistic binding of the Vibrio fischeri LuxR transcriptional activator domain and RNA polymerase to the lux promoter region. Proceedings of the National Academy of Sciences, 91(26), 12619-12623. 
Stoll, F. M., Wilson, C. R., Faraut, M. C., Vezoli, J., Knoblauch, K., \& Procyk, E. (2016). The effects of cognitive control and time on frontal beta oscillations. Cerebral Cortex, 26(4), 1715-1732.

Strait, C.E., Blanchard, T.C., Hayden, B.Y. (2014). Reward Value Comparison via Mutual Inhibition in Ventromedial Prefrontal Cortex. Neuron 82:1357-1366.

Strait, C. E., Sleezer, B. J., \& Hayden, B. Y. (2015). Signatures of value comparison in ventral striatum neurons. PLoS Biol, 13(6), e1002173.

Strait, C. E., Sleezer, B. J., Blanchard, T. C., Azab, H., Castagno, M. D., \& Hayden, B. Y. (2016). Neuronal selectivity for spatial positions of offers and choices in five reward regions. Journal of neurophysiology, 115(3), 1098-1111.

Strandburg-Peshkin, A., Farine, D. R., Couzin, I. D., \& Crofoot, M. C. (2015). Shared decision-making drives collective movement in wild baboons. Science, 348(6241), 1358-1361.

Stroop, J. R. (1935). Studies of interference in serial verbal reactions. Journal of experimental psychology, 18(6), 643.

Sumpter, D.J.T. (2006). The principles of collective animal behaviour. Philos Trans R Soc Lond B Biol Sci 361:5-22.

Theraulaz G, Bonabeau E (1999) A Brief History of Stigmergy. Artif Life 5:97-116.

Theraulaz, G., Bonabeau, E., \& Deneubourg, J. L. (1998). The origin of nest complexity in social insects. Complexity, 3(6), 15-25.

Treherne, J. E., \& Foster, W. A. (1981). Group transmission of predator avoidance behaviour in a marine insect: the Trafalgar effect. Animal Behaviour, 29(3), 911917.

Turken, A.U., \& Swick, D. (1999). Response selection in the human anterior cingulate cortex. Nature Neuroscience. 2:920-925

Ursu, S., Stenger, V.A., Shear, M.K., Jones, M.R., \& Carter, C.S. (2003). Overactive action monitoring in obsessive-compulsive disorder: evidence from functional magnetic resonance imaging. Psychological Science. 14: 347-354

Van Veen, V., Krug, M. K., \& Carter, C. S. (2008). The neural and computational basis of controlled speed-accuracy tradeoff during task performance. Journal of Cognitive Neuroscience, 20(11), 1952-1965.

Visick, K. L., Foster, J., Doino, J., McFall-Ngai, M., \& Ruby, E. G. (2000). Vibrio fischeri lux genes play an important role in colonization and development of the host light organ. Journal of Bacteriology, 182(16), 4578-4586.

Volkow, N.D., Fowler, J.S. (2000). Addiction, a disease of compulsion and drive: involvement of the orbitofrontal cortex. Cerebral Cortex. 10:318-325.

Wallraff, H.G. (1978). Social interrelations involved in migratory orientation of birds: possible contributio of field studies. Oikos 30:401-404.

Wang, X. J., \& Kennedy, H. (2016). Brain structure and dynamics across scales: in search of rules. Current opinion in neurobiology, 37, 92-98. 
Wang, Z., Dai, Z., Gong, G., Zhou, C., \& He, Y. (2015) Understanding structuralfunctional relationships in the human brain: A large-scale network perspective The Neuroscientist 21:290-305.

Ward, A.J.W., Sumpter, D.J.T., Couzin, I.D., Hart, P.J.B., \& Krause, J. (2008). Quorum decision-making facilitates information transfer in fish shoals. Proc Natl Acad Sci 105:6948-6953.

Waters, C. M., \& Bassler, B. L. (2005). Quorum sensing: cell-to-cell communication in bacteria. Annu. Rev. Cell Dev. Biol., 21, 319-346.

Weiner, N., \& others (1948). Cybernetics. New York: Wiley.

Wilson, E. O. (1971). The insect societies. The insect societies.

Wilson, R.C., Takahashi, Y.K., Schoenbaum, G., \& Niv, Y. (2014). Orbitofrontal Cortex as a Cognitive Map of Task Space. Neuron 81:267-279.

Wilson, C. R., Gaffan, D., Browning, P. G., \& Baxter, M. G. (2010). Functional localization within the prefrontal cortex: missing the forest for the trees?. Trends in neurosciences, 33(12), 533-540.

Wickelgren, W. A. (1977). Speed-accuracy tradeoff and information processing dynamics. Acta psychologica, 41(1), 67-85.

Zhu, J., \& Winans, S. C. (1999). Autoinducer binding by the quorum-sensing regulator TraR increases affinity for target promoters in vitro and decreases TraR turnover rates in whole cells. Proceedings of the National Academy of Sciences, 96(9), 4832-4837. 